\title{
Multi-model assessment of trends, variability and drivers of terrestrial carbon uptake in India
}

\author{
Ananya S RaO ${ }^{1, *}$, Govindasamy Bala ${ }^{1}, \mathrm{~N}$ H Ravindranath ${ }^{2}$ and Rama Nemani ${ }^{3}$ \\ ${ }^{1}$ Centre for Atmospheric and Oceanic Sciences, Indian Institute of Science, Bangalore 560 012, India. \\ ${ }^{2}$ Centre for Sustainable Technologies, Indian Institute of Science, Bangalore 560 012, India. \\ ${ }^{3}$ NASA Ames Research Center, Moffett Field, Mountain View, CA 94035, USA. \\ ${ }^{*}$ Corresponding author.e-mail: ananya@caos.iisc.ernet.in
}

MS received 8 August 2017; revised 5 September 2018; accepted 29 October 2018; published online 2 April 2019

A multi-model-based assessment is made to assess the trends and variability in the land carbon uptake in India during the period 1901-2010. Data from nine models, used in a recent land surface model inter-comparison project called TRENDY, are used for this purpose. Our analysis is focused on the trends and variability in the net primary productivity (NPP), net ecosystem productivity (NEP) and net ecosystem exchange (NEE). The multi-model mean NPP shows a positive trend of $2.03 \%$ per decade during this period. The NEP, which is the difference between NPP and heterotrophic respiration, has a mean value of $-0.138 \pm 0.086 \mathrm{Pg} \mathrm{Cyr}^{-1}$ over this region. According to our analysis of TRENDY multimodels, the inter-annual variation in NPP and NEP is strongly driven by precipitation, but remote drivers such as El Niño Southern Oscillation (ENSO) and Indian Ocean Dipole (IOD) do not have a strong influence. The water use efficiency (WUE) shows an increase of about 25\% over the 110-yr period. Our multi-model-based estimate of the cumulative NEE is $0.613 \pm 0.1 \mathrm{Pg} \mathrm{C}$ during 1901-2010, indicating that the Indian terrestrial ecosystem was neither a strong source nor a significant sink during this period. However, we caution that our conclusion is based on a limited set of offline land models, and the results presented here have large uncertainties due to model resolution and parameterisation of various land surface processes, the inadequate validation procedures and the use of limited number of models and land use change data sets. Further investigations using more observational data, rigorous validation using extensive observational data sets and a set of comprehensive coupled models that include several feedbacks between land, atmosphere, ocean and the cryosphere are needed to assess the robustness of our results.

Keywords. TRENDY multi-model; regional carbon cycle; trends in NPP; NEP over India; water use efficiency.

\section{Introduction}

Plant photosynthesis removes $\mathrm{CO}_{2}$ from the atmosphere (photosynthesis scaled to a global scale is called the gross primary productivity (GPP)) and fixes carbon into plant leaves, which then cycles through plant matter, litter and soil carbon and is released back into the atmosphere

Supplementary material pertaining to this article is available on the Journal of Earth System Science website (http://www. ias.ac.in/Journals/Journal_of_Earth_System_Science). 
by autotrophic (plant, Ra), heterotrophic (soil microbial and animal, $\mathrm{Rh}$ ) respiration and disturbance processes such as fires and land use change (Beer et al. 2010). Factors influencing the exchange of carbon between the land and atmosphere are changes in atmospheric $\mathrm{CO}_{2}$ concentration, nitrogen deposition, variable climate and direct human actions such as land conversion (Devaraju et al. 2015; Schimel et al. 2015), the effects of which are manifested over seasonal to millennial timescales (Bolin et al. 2000; Schimel et al. 2001). Many global and regional studies investigated the amount of carbon taken up or released by the terrestrial ecosystems to the atmosphere to determine whether the region of interest is a sink or source of carbon.

The carbon feedbacks need to be understood better at the regional level, so that uncertainty at the global scale can be reduced (Le Quere et al. 2013; Canadell 2011). Thompson et al. (2016) used an ensemble of several atmospheric inverse modelling systems and atmospheric observations of $\mathrm{CO}_{2}$ concentration to estimate the land biosphere fluxes (natural, land use change and fires) for Asia. They found that the Asian land biosphere was a net sink of $-0.46(-0.70$ to 0.24$)$ petagram of carbon per year $\left(\mathrm{PgC}_{\mathrm{yr}}{ }^{-1}\right.$; fluxes are positive when they are directly from land to atmosphere) for 1996-2012 and was mostly located in East Asia, while in South and Southeast Asia, the land biosphere was close to carbon neutral. Haverd et al. (2013) for the period 1990-2011, in the context of estimates over last two centuries, found that climate variability and rising $\mathrm{CO}_{2}$ made maximum contributions to biospheric carbon accumulation in Australia. Patra et al. (2013), along with inversions of atmospheric $\mathrm{CO}_{2}$ data, field observations and satellite data, used data from multiple models which are a part of the carbon cycle model inter-comparison project called TRENDY (Sitch et al. 2015), a part of the Global Carbon Project, where each model uses a specified protocol, to simulate the trends and variability in terrestrial carbon (Piao et al. 2013; Sitch et al. 2013; http://dgvm.ceh.ac.uk/system/files/ Trendyprotocol\%20Nov20110.pdf). They found that the net biospheric $\mathrm{CO}_{2}$ flux in South Asia was a sink, estimated at $-104 \pm 150$ teragram of carbon per year (Tg C yr ${ }^{-1}$ ) during 2007-2008. Based on the bottom-up approach, the net biospheric $\mathrm{CO}_{2}$ flux sink is estimated to be $-191 \pm$ $193 \mathrm{Tg} \mathrm{Cyr}^{-1}$ during the period 2000-2009. Including the emissions from the combustion of fossil fuels of $444 \mathrm{Tg} \mathrm{Cyr}^{-1}$ for the 2000s, they estimated a net $\mathrm{CO}_{2}$ land-atmosphere flux of $297 \mathrm{Tg} \mathrm{Cyr}^{-1}$. Cervarich et al. (2016) also used the TRENDY data along with other bottom-up approaches to estimate the terrestrial carbon budget of South and Southeast Asia. They found that the Indian terrestrial ecosystems were a sink for atmospheric $\mathrm{CO}_{2}$ from 2000 to 2013, but a net source of carbon when fossil fuel emissions were also considered.

In India, carbon in the soil forms about $54 \%$ of the land carbon stocks (Brown et al. 1993), and the rest is in biomass. The spatio-temporal variability of net primary productivity $(\mathrm{NPP}=\mathrm{GPP}-\mathrm{Ra})$ over India has been assessed using ground inventory, remotely sensed satellite-derived data and model-based approaches (Hingane 1991; Chhabra and Dadhwal 2004a; Nayak et al. 2010; Singh et al. 2011; Dadhwal 2012; Bala et al. 2013; Goroshi et al. 2014; Banger et al. 2015). Using the normalised difference vegetation index (NDVI) and the terrestrial carbon cycle model CarnegieAMES-Stanford-Approach (CASA), Nayak et al. (2013) estimated the linear growth rate of annual $\mathrm{NPP}$ as $0.005 \mathrm{Pg} \mathrm{C} \mathrm{yr}^{-2}$ which is equivalent to $8.5 \%$ over India during 1981-2006. Bala et al. (2013), using advanced very high-resolution radiometer (AVHRR)-derived NPP for the period 1982-2006, estimated an increase in total NPP over the country from $0.78 \mathrm{PgC} \cdot \mathrm{yr}^{-1}$ in 1982 to $0.86 \mathrm{PgC} \cdot \mathrm{yr}^{-1}$ in 2006 ( $\sim 4 \%$ per decade). However, Singh et al. (2011) estimated higher values of NPP between 3.56 and $4.57 \mathrm{Pg} \mathrm{Cyr}^{-1}$ for the period 1981-2000. Banger et al. (2015) used a process-based model for the estimation of terrestrial NPP and found an increasing trend caused by elevated $\mathrm{CO}_{2}$ concentration, land use change and nitrogen deposition over India for the period 1901-2010 and also found that NPP increased from 1.2 to $1.7 \mathrm{Pg} \mathrm{Cyr}^{-1}(\sim 3.8 \%$ per decade). The NPP over India is likely to increase in the future. Bala et al. (2011), using a terrestrial biosphere model, projected NPP to increase by about $71 \%$ by 2100 under the SRES A2 scenario mainly because of $\mathrm{CO}_{2}$ fertilisation. The mean NPP estimates for India vary widely among these studies, but they all found a positive trend in NPP in recent decades.

Net ecosystem productivity (NEP) that is defined as the difference between NPP and Rh is used in many studies to assess the net flux of carbon (in the absence of disturbance fluxes) between the land and the atmosphere. Dadhwal (2012) and Nayak et al. (2011) modelled the monthly NEP over India for a recent 26-yr period (1981-2006) using a terrestrial ecosystem model and inferred 
that India has been a net sink of atmospheric $\mathrm{CO}_{2}$ with total annual uptake of $9.5 \mathrm{Tg} \mathrm{C} \mathrm{yr}^{-1}$ from 1981 to 2006. This trend in terrestrial ecosystem uptake over India for the same period is also analysed by Nayak et al. (2015), where it is found that in the early 1980s, the Indian terrestrial biosphere was a source, and it later became a sink of carbon from 1986 to 2006. Chhabra and Dadhwal (2004b) used a simple book-keeping approach, the summary of studies on carbon release from Indian forests in an age-class model, to find that the mean annual net $\mathrm{C}$ flux from Indian forests due to deforestation, afforestation and phytomass degradation was $47 \mathrm{Tg} \mathrm{C}_{\mathrm{yr}}{ }^{-1}$ during $1880-1996$.

All the above studies do not address the question if the Indian land has been a cumulative sink or source since the pre-industrial period. In this study, we analyse the regional carbon dynamics for the historical time period of 1901-2010, using the results from multiple process-based models, and present the trends and variability in NPP and Rh with the goal of identifying whether the region has been a sink or source of carbon. The drivers of the changes seen in NPP and Rh are then examined and compared. The water use efficiency (WUE) for the entire region over the historical period is also analysed. Thus, our study quantifies the long-term historical trends and variability in the terrestrial carbon cycle over the Indian region based on outputs from multiple terrestrial carbon cycle models and also assesses the drivers of the changes.

\section{Materials and methods}

The region of analysis in this study is India, which is home to around 1.25 billion people and covers a land area of 2.9 million $\mathrm{km}^{2}$. Predominantly, an agrarian economy, $52.8 \%$ of the total land area is under agriculture, majority of which is dependent on the Indian monsoon or the season of concentrated rain (NATCOM2 2012). The country is a mega-biodiversity country and $21.34 \%$ of the total geographical area is under forests (ISFR 2015). Our work covers the entire geographical land area of India. The land use map of India is shown in the supplementary section (figure S1), and our work covers the entire geographical land area of India covering all the land use categories.

Terrestrial carbon cycle data for the 1901-2010 period are obtained from the TRENDY (trends in net land-atmosphere carbon exchanges) land surface models for the Indian region. The model results used here are from TRENDY-v1 (Sitch et al. 2015). Data from TRENDY are a result of global modelling and synthesis efforts by a consortium of Dynamic Global Vegetation Model (DGVM) groups as a part of the Global Carbon Project (Sitch et al. 2013). A set of nine land surface models (supplementary table S1) were driven with common forcing data for simulations over the historical period, 1860-2010, and the outputs are available at http://www-lscedods.cea.fr/ invsat/RECCAP/. The outputs from two simulations are used here - the S1 simulation which has atmospheric $\mathrm{CO}_{2}$ concentration alone varying and the S2 simulation where both the climate forcing and atmospheric $\mathrm{CO}_{2}$ are varying. Simulation S2 represents the control case or the actual historical evolution of the system, and the S1 simulation is used to make comparisons with $\mathrm{S} 2$ to obtain the individual effect of varying climate alone with $\mathrm{CO}_{2}$ kept constant (S2-S1). The changes in $\mathrm{S} 1$ simulation with time are used to infer the effect of increasing $\mathrm{CO}_{2}$ with climate kept constant. An additional simulation, $\mathrm{S} 3$, has $\mathrm{CO}_{2}$, climate and the land use varying with time as described in Cervarich et al. (2016), but only four of the nine models that performed S3 simulations are the same as in S2. The S3 simulation is a part of the TRENDY $\mathrm{v} 2$, and to avoid mix-up of simulations from different model versions, we restrict our analysis to the S1 and S2 simulations of TRENDY-v1.

The TRENDY models use the Climatic Research Unit (CRU) and National Center for Environmental Prediction (NCEP) historical forcing data for 1901-2010 as the climate forcing to drive the models. The CRU data set has been validated over India for precipitation from the India Meteorological Department (IMD) by Prakash et al. (2015). The CRU data set captures well the inter-annual variability in precipitation, and the comparison of the CRU data set with the IMD data during the south-west monsoon averaged for the period 1979-2005 gives a pattern correlation of 0.87 . The temperature data from CRU are validated over India by Basha et al. (2017). They found that the mean bias between IMD and CRU data set is less than $\pm 1 \mathrm{~K}$, except for the north-eastern part of the country and the Himalayan regions. The input data have a spatial resolution of $0.5^{\circ} \times 0.5^{\circ}$ and a time resolution of $6 \mathrm{~h}$. These models assume a constant land use throughout the simulation. It is likely that the carbon stocks (e.g., vegetation carbon) and fluxes (e.g., NPP) are reduced because of changing land cover and land use change patterns 
(Kaul et al. 2009). Hence, the use of constant land use change may lead to inconsistency in the results simulated by the TRENDY models. CLM4CN and OCN simulate the nitrogen cycle explicitly, and the atmospheric nitrogen deposition data are sourced from Jean-Francois Lamarque, through personal communication and Dentener et al. (2006), respectively (Sitch et al. 2013). Soil map from Harmonized World Soil Database (HWSD) is used by all models. The outputs from the nine land surface models were at different resolutions (table S1). The version of TRENDY data used for the study had the data regridded to $1^{\circ} \times 1^{\circ}$ resolution for the sake of uniformity. The data are available at http:// www-lscedods.cea.fr/invsat/PEYLIN/TRENDY/.

For validation of the models for the Indian region, the data mostly derived from satellite observations are used for comparison with multimodel TRENDY outputs. This includes satellitederived NPP data for the Indian region from 1982 to 2006 at $0.25^{\circ} \times 0.25^{\circ}$ resolution, which are the same as in Nemani et al. (2003). The GPP data for validation of the model results are from 1982 to 2009 at a resolution of $0.5^{\circ} \times 0.5^{\circ}$ from NASA (and was obtained from Hiro Hashimoto through personal correspondence). The evapotranspiration (ET) data for 1983-2006 at a resolution of $1^{\circ} \times 1^{\circ}$ are from NASA Earth Data SDAT (Spatial Data Access Tool - http://webmap.ornl. gov/wcsdown/dataset.jsp?ds_id=10020). The soil carbon data at $0.5^{\circ} \times 0.5^{\circ}$ resolution from Data and Information System (DIS) of the International Geosphere Biosphere Programme (IGBP) are also used for validation of the multi-model soil carbon output. All the above data are regridded to a common resolution of $1^{\circ} \times 1^{\circ}$ as discussed above. The data products, sources, resolution and time period of availability are summarised in supplementary table S2. Differences in spatial and temporal resolutions of observed data and the model results would have major influence on small spatial and shorter timescales. However, our study is focused on climate statistics such as temporal mean, variability and averages over large spatial and temporal scales, and hence, our results are less likely to be influenced by these differences.

The algorithm used to obtain the satellitederived NPP data set has been validated using Bigfoot data for North America and Brazil at nine sites representing a range of biomes (Turner and Ritts 2006), Ameriflux data from North America (Heinsch and Zhao 2006) and global ecosystem model-date inter-comparison (EMDI) NPP data set (Zhao et al. 2005).

The GPP data used here from NASA MODIS algorithm has been validated for a mixed forest site in the Nepalese Himalayas and multiple biomes in China (Gebremichael and Barros 2006; Zhu 2016), and the ET data are validated for the Free State province of South Africa (Moeletsi and Walker 2012).

For determining the climatic drivers of the trends and variability in the land carbon fluxes from the TRENDY models, we used the same data that were used to drive the TRENDY simulations - climate data from CRU (temperature and precipitation) at $0.5^{\circ} \times 0.5^{\circ}$ resolution. The annual global mean atmospheric $\mathrm{CO}_{2}$ data from NOAA-Earth System Research Laboratory (ESRL) - ftp://ftp.cmdl. noaa.gov/ccg/co2/trends/co2_annmean_mlo.txt for the years 1959-2010 are also used in our analysis of trends and variability.

The net ecosystem exchange (NEE) is defined as follows:

$$
\begin{aligned}
\mathrm{NEE} & =\mathrm{Rh}-\mathrm{NPP}+\text { Fire flux }+\mathrm{LUF} \\
& =\mathrm{NEP}+\text { Fire flux }+\mathrm{LUF},
\end{aligned}
$$

where Fire flux is the emission of carbon to the atmosphere through burning of biomass and LUF is the land use change flux.

To estimate the NEE for the region, we use carbon flux due to fire (fFire) from five of the TRENDY models (CLM4, LPJ, LPJ_GUESS, OCN and SDGVM). The flux from land use change is obtained from the land component (CLM4) of Community Earth System Model (CESM) simulations for the historical period (Devaraju et al. 2015). CLM4 model uses transient land use and land cover change data set from version 1 of the Land-Use History A product (LUHa.v1), covering the period 1850-2005. The land cover information includes fractional grid cell coverage by crops, pasture and primary and secondary natural vegetation and is provided at $0.5^{\circ} \times 0.5^{\circ}$ grid resolution (Oleson et al. 2010).

The influences of remote climatic phenomena such as the El Niño Southern Oscillation (ENSO) and Indian Ocean Dipole (IOD) on the land carbon fluxes are also assessed using the simple linear regression analysis in this study. Several indices are used to define ENSO; however, in this study, we use the multivariate ENSO index (MEI) obtained from NOAA-ESRL - http://www.esr/noaa.gov/ 
psd/enso/mei.ext (Wolter and Timlin 1993, 1998) for 1950-2010. The IOD is defined by the dipole mode index (DMI), which describes the difference in sea surface temperature anomaly between the tropical western Indian Ocean $(50.8 \mathrm{E} \pm 70.8 \mathrm{E}$, $10.8 \mathrm{~S} \pm 10.8 \mathrm{~N})$ and the tropical south-eastern Indian Ocean $(90.8 \mathrm{E} \pm 110.8 \mathrm{E}, 10.8 \mathrm{~S} \pm$ Equator; Saji et al. 1999). The DMI data are obtained for the period from 1958 to 2010 from the link http://www.jamstec.go.jp/frsgc/research/d1/iod/ e/iod/dipole \_mode\_index.html.

\section{Results and discussion}

Simulation S2 (described in section 2) is used for most of the analysis as it has both varying $\mathrm{CO}_{2}$ and climate, likely closer to the observed terrestrial carbon cycle in the historical period.

\subsection{TRENDY validation}

Four of the multi-model output variables are validated with observational data: NPP, GPP, soil carbon and ET. As discussed in the previous section, the nine-model ensemble mean TRENDY NPP data from 1982 to 2006 (simulation S2) are extracted for the Indian region, and the temporal mean of all the models is calculated. This is compared with the mean observational NPP for the region derived from satellite data (Nemani et al. 2003; Bala et al. 2013) for the same period. The results show an overall high positive spatial correlation of 0.734 between the multi-model mean NPP and satellite-derived NPP (as shown in figure 1). The satellite-derived NPP is maximum in the north-eastern parts of India and also in few regions along the Western Ghats in the south-western parts of India. The models capture the large NPP values in the north-east but not in the Western Ghats, probably because the width of the Western Ghats is less than $100 \mathrm{~km}$ in most parts (Tawde Sayli and Singh 2014), and the coarse resolution of the models is unable to resolve the Ghats. Satellite-derived NPP is smaller in the Northern Himalayas, where there is very little vegetation and in the north-western India, comprising the Thar Desert. Goroshi et al. (2014) found similar regional differences in NPP for the year 2009. The spatial mean NPP over India for $1982-2006$ from satellite data is $0.27 \mathrm{~kg} \mathrm{C} \mathrm{m}^{-2} \mathrm{yr}^{-1}$ $\left(0.83 \mathrm{Pg} \mathrm{C} \mathrm{yr}^{-1}\right)$ with a standard deviation of 0.25 $\mathrm{kg} \mathrm{C} \mathrm{m}{ }^{-2} \mathrm{yr}^{-1}$. For the same period, the TRENDY mean NPP over India is $0.511 \mathrm{~kg} \mathrm{C} \mathrm{m}^{-2} \mathrm{yr}^{-1}$ $\left(1.52 \mathrm{Pg} \mathrm{C} \mathrm{yr}^{-1}\right)$ with a standard deviation of 0.28 $\mathrm{kg} \mathrm{C} \mathrm{m} \mathrm{yr}^{-1}$. Hence, the mean bias is too large $\left(0.24 \mathrm{~kg} \mathrm{C} \mathrm{m}^{-2} \mathrm{yr}^{-1}\right)$, but it should be recognised that the satellite-derived NPP is also a product of retrieval algorithms that make use of models to process the raw data. As in many climate modelling studies, the major assumptions are that the bias is the same throughout the simulation period. Therefore, the trend and variability are not affected by such a large difference: the trend and variability analysis actually deals with anomalies relative to a mean. In this case, the satellite-derived NPP product used utilises observations from the AVHRR in conjunction with a light use efficiency model implemented for the MODIS sensor. As discussed in section 1, the estimation of NPP over India varies widely among studies. The root mean square error (RMSE) between the models and satellite-derived NPP is $0.16 \mathrm{~kg} \mathrm{C} \mathrm{m}^{-2} \mathrm{yr}^{-1}$.

The satellite-derived GPP is obtained for the years 1982-2009. The TRENDY multi-model mean GPP is extracted for the same time period, and it shows a spatial correlation of 0.68 with the satellite-derived GPP, with the TRENDY models overestimating the GPP in central and eastern parts of the country. The satellite-based observational data set has a few grid points missing in the northern tip of the region, giving the spatial map a slight distortion (figure 1). The satellitederived GPP shows large values in the north-east and a few grid points in the Western Ghats. Mean GPP observed for the whole time period is $0.52 \mathrm{~kg} \mathrm{C} \mathrm{m}^{-2} \mathrm{yr}^{-1}\left(1.57{\mathrm{PgC} \mathrm{yr}^{-1}}^{-1}\right)$ with a standard deviation of $0.7 \mathrm{~kg} \mathrm{C} \mathrm{m}^{-2} \mathrm{yr}^{-1}$ and the TRENDY multi-model mean GPP for the same time period is $0.79 \mathrm{~kg} \mathrm{C} \mathrm{m}^{-2} \mathrm{yr}^{-1}\left(2.35 \mathrm{Pg} \mathrm{C}^{-1}\right)$ with a standard deviation of $1 \mathrm{~kg} \mathrm{C} \mathrm{m}^{-2} \mathrm{yr}^{-1}$. The spatial RMSE for this period is $0.6 \mathrm{~kg} \mathrm{C} \mathrm{m}^{-2} \mathrm{yr}^{-1}$. The spatial patterns of temporal correlation between the TRENDY multi-model mean and satellite-derived GPP for the period 1982-2009 and NPP for the period 1982-2006 are shown in figure S2. This figure essentially assesses the ability of the models to simulate the phases in the inter-annual variability. We find that the correlation is mostly positive over India except in the dry regions in the north-western India (figure S2) where the absolute values of GPP and NPP are small. The lack of large positive correlation indicates that the representation of key physical and biological processes in the models is inadequate. 

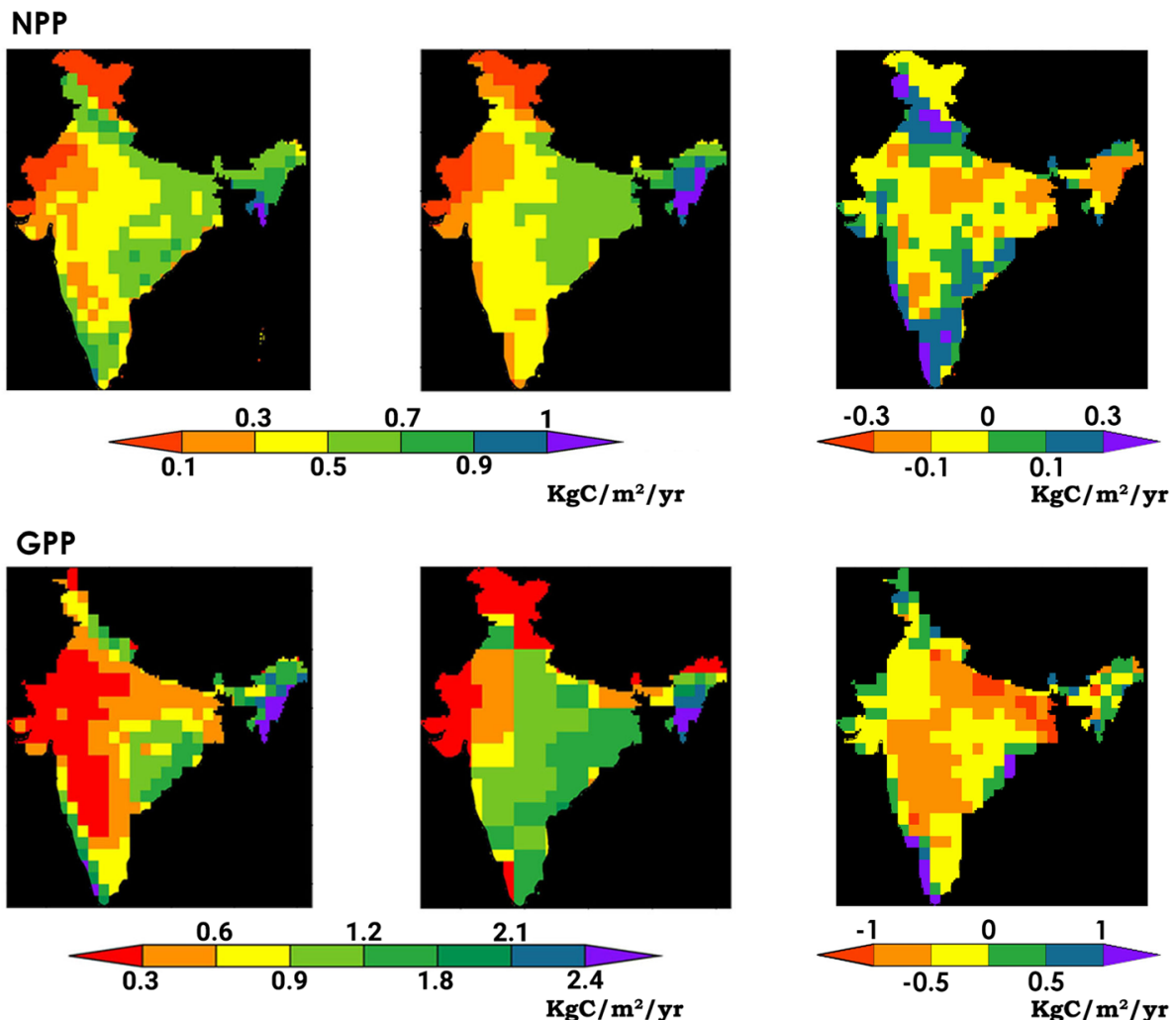

Figure 1. The spatial pattern of mean annual TRENDY NPP and GPP in comparison with observational data. Left panels show the spatial patterns of observational data, middle panels show the spatial pattern of TRENDY multi-model mean values for the same time period, and the right panels show the difference between the observational data and TRENDY multi-model mean. The TRENDY multi-model mean NPP is validated with satellite-derived NPP from 1981 to 2006 . Multi-model mean GPP is validated with satellite-derived GPP from 1982 to 2009.

The soil carbon for the Indian region from the eight TRENDY models is validated with IGBP (1998) soil carbon data (figure 2). The spatial correlation is 0.5 , suggesting large differences in regional patterns. The TRENDY models overestimate the soil carbon in the north-eastern India and underestimate it in the south and western parts of the country. Although the mean bias is small, the spatial variations are large: the spatial mean soil carbon from IGBP estimate is $4.62 \mathrm{~kg} \mathrm{C} \mathrm{m}^{-2}$ (13.72 Pg C) with a standard deviation of $0.8 \mathrm{~kg} \mathrm{C} \mathrm{m}^{-2}$ and the multi-model TRENDY mean over India is $5.19 \mathrm{~kg} \mathrm{C} \mathrm{m}^{-2}(15.41 \mathrm{Pg} \mathrm{C})$ with a standard deviation of $1.3 \mathrm{~kg} \mathrm{C} \mathrm{m}^{-2}$. The RMSE is $3.25 \mathrm{~kg} \mathrm{C} \mathrm{m}^{-2}$ which indicates that spatially there are large differences in the model estimates and the observations.

Ensemble mean ET from the TRENDY models is also validated with satellite-derived ET (http:// webmap.ornl.gov/wcsdown/dataset.jsp?ds $\backslash$ id $=10$ 020) for the period 1983-2006. A spatial correlation of 0.57 is calculated between the multi-model mean and the observations. The TRENDY models overestimate the ET in the eastern parts of the country (figure 2). The mean satellite-derived ET for the period is $1071 \mathrm{~mm} \mathrm{yr}^{-1}$ with a standard deviation of $242 \mathrm{mmyr}^{-1}$. The TRENDY mean ET is $1147 \mathrm{mmyr}^{-1}$ with a standard deviation of $316 \mathrm{~mm} \mathrm{yr}^{-1}$, indicating a small mean bias ( $\sim 10 \%)$ but overestimation of spatial variations. The RMSE is $51.7 \mathrm{mmyr}^{-1}$. The fair spatial correlation between the multi-model mean values and the observational values indicates fair agreement between the TRENDY model ensemble and observational data for the Indian region. We recognise that the validation procedure used in our study is inadequate. However, the validation performed here is a standard procedure adopted in other similar studies (e.g., Maignan et al. 2011; Zhang et al. 2015). Although site-level validations are important, for a national-scale study like this, validation with satellite-based data sets is more in practice. Validation of large-scale models that are used for large-scale assessments with site-level measurements would not cover the entire region in a uniform basis. It is very likely that the inadequate validation could contribute to large uncertainty in the results and conclusions 

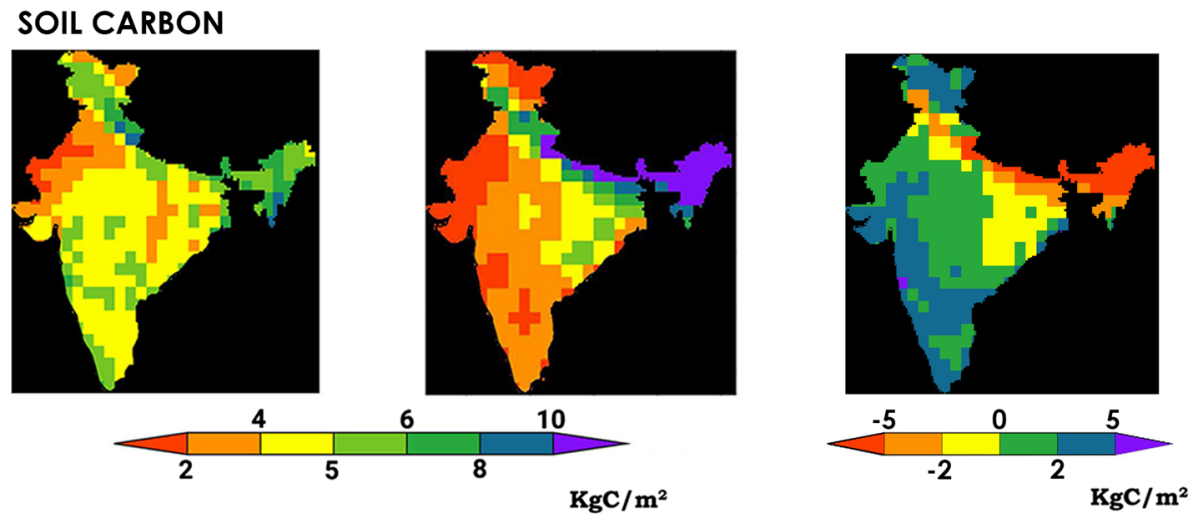

EVAPO-TRANSPIRATION
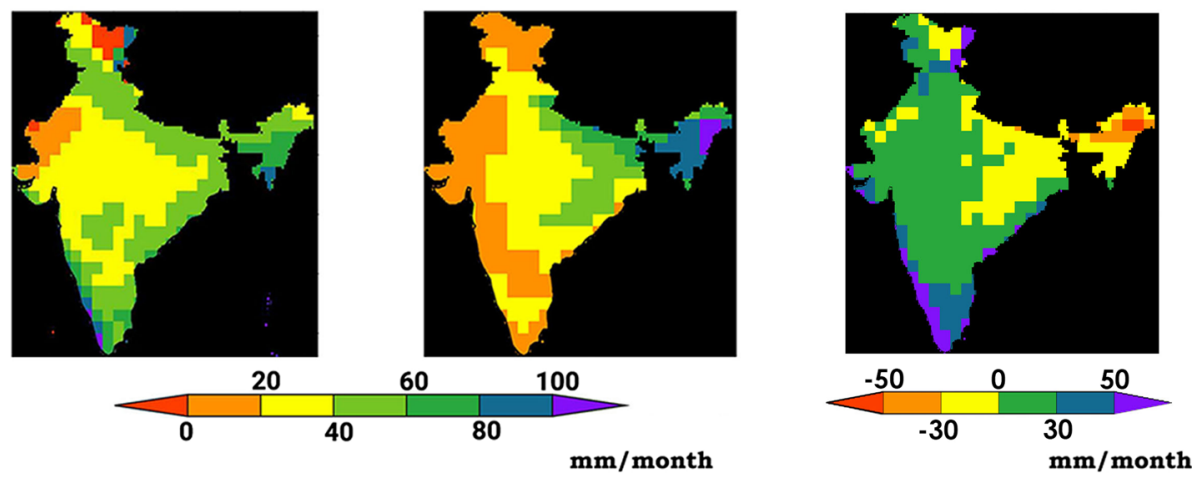

Figure 2. The spatial pattern of TRENDY mean annual ET and soil carbon in comparison with observational data. Left panels show the spatial patterns of observational data, middle panels show the spatial pattern of TRENDY multi-model mean values for the same time period and the right panels show the difference between the observational data and TRENDY multi-model mean. TRENDY soil carbon is validated with IGBP soil carbon developed in the year 1998. TRENDY ET is validated with MODIS-derived ET from 1983 to 2006.

presented below. We plan to improve our validation in a future study with the availability of more site-level observational data sets at a national scale.

\subsection{TRENDY multi-model mean results}

\subsubsection{Global and Indian region NPP and NEP}

The multi-model mean global NPP from TRENDY for $1901-2010$ is calculated as $56.39 \pm 3.8 \mathrm{Pg} \mathrm{C} \mathrm{yr}^{-1}$ and global NPP for the last $30 \mathrm{yr}$ from 1981 to 2010 is $61.986 \pm 2.1 \mathrm{PgCyr}^{-1}$, suggesting an increasing trend in NPP globally. From 1990 to 2000 the ensemble mean NPP is $62.9{\mathrm{PgC} \mathrm{yr}^{-1}}^{-1}$ which is consistent with Sitch et al. (2013) who used a similar set of nine models from an earlier version of TRENDY project for their global land carbon trend analysis (which included the JULES model instead of TRIFFID). A previous study by Cramer et al. (1999) estimated global NPP from 17 model inter-comparisons in the range of 44.4-66.3 $\mathrm{Pg} \mathrm{C} \mathrm{yr}^{-1}$. NPP for the Indian region is around $2 \%$ of the global NPP and the mean NPP estimated by the TRENDY models from 1981 to 2010 is $1.53 \pm 0.08 \mathrm{PgCyr}^{-1}$. This is a smaller value than the remote sensing-based estimates of NPP by Chhabra and Dadhwal (2004a) for June 1998 to May 1999 (2.18 Pg C) indicating that the Indian landmass with $1.45 \%$ of the world's total geographical area accounts for $\sim 2.7-5.5 \%$ to the global NPP estimates (40-80 $\mathrm{Pg} \mathrm{Cyr}^{-1}$; Cramer et al. 1999). It should be noted that the time period considered for the satellite data is different between our study and Chhabra and Dadhwal (2004a). The satellite-based estimate of NPP by Chhabra and Dadhwal (2004a) is only for a year (June 1998-May 1999). This 1-yr estimate by their study is larger than the TRENDY mean NPP $\left(1.53 \pm 0.08 \mathrm{Pg} \mathrm{C} \mathrm{yr}^{-1}\right)$ from 1981 to 2010 . Inter-annual variability is likely a cause for the differences.

The multi-model mean global NEP(heterotrophic respiration minus NPP) for the recent 30-yr period (1981-2010) and for the entire time period of 19012010 is calculated as $-5.243 \pm 0.9$ and $-4.157 \pm$ $0.9 \mathrm{Pg} \mathrm{Cyr}^{-1}$, respectively. Previous estimates of global NEP range from as large as $-10 \mathrm{Pg} \mathrm{C} \mathrm{yr}^{-1}$ 

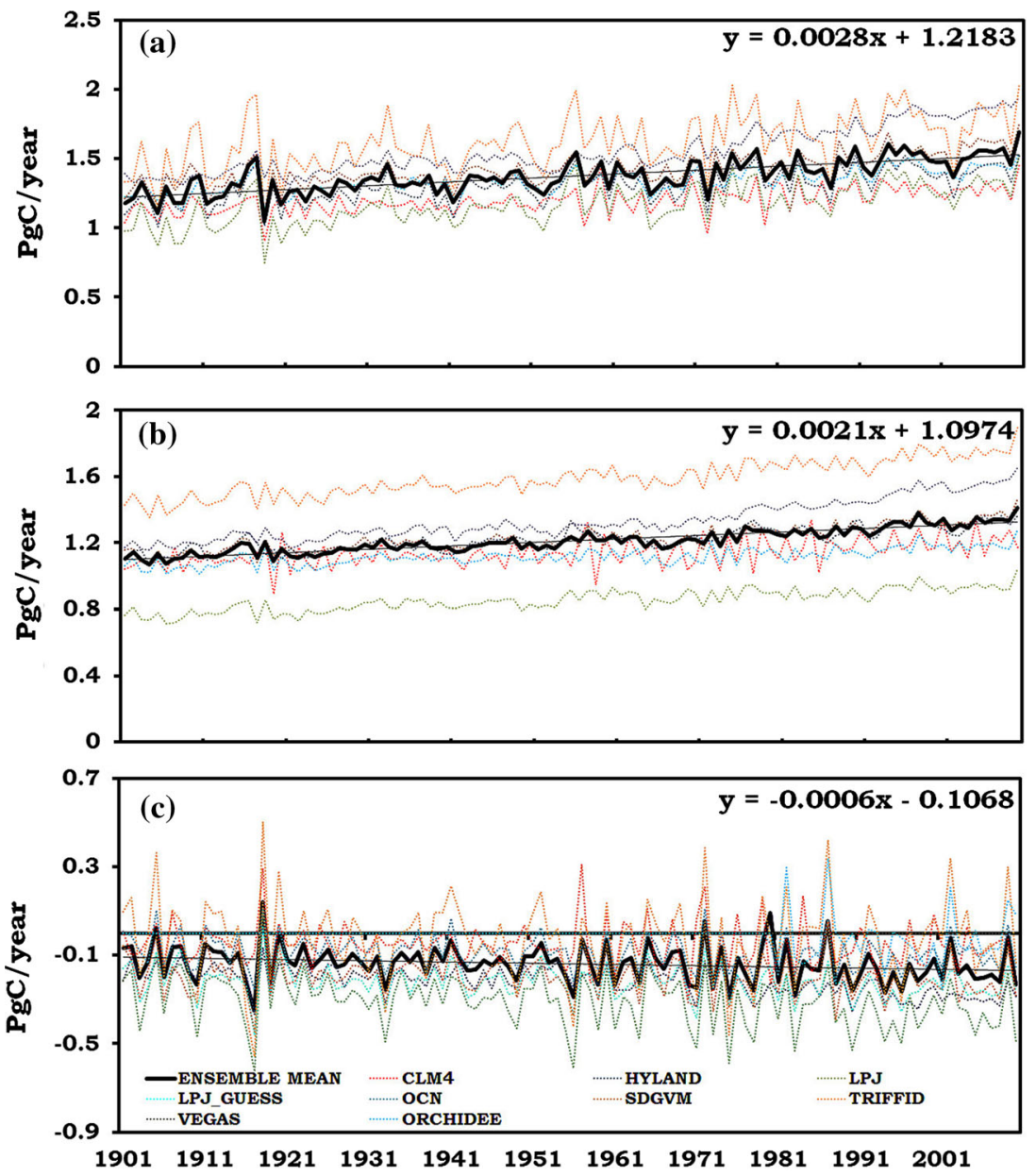

Figure 3. The long-term temporal evolution of domain averaged (a) NPP, (b) Rh and (c) NEP (1901-2010) over India. Multi-model means are represented in thick lines, and individual model values are in dotted lines. A linear trend line is fitted to each of the multi-model means, and the regression relationship is displayed in the top right corner of each panel.

to as small as $0.8{\mathrm{PgC} \mathrm{yr}^{-1}}^{-1}$ (Xiao et al. 1997; Schulze et al. 2000).

\subsubsection{Trends in NPP, NEP and Rh for Indian region}

The TRENDY mean NPP from 1901 to 2010 is $1.373 \pm 0.087 \mathrm{PgC}^{-1}$ for India and the mean $\mathrm{Rh}$ for the same period is $1.211 \pm 0.073{\mathrm{Pg} \mathrm{C} \mathrm{yr}^{-1}}^{-1}$ (figure 3 ). We find a gradual increase in the $\mathrm{NPP}$ of the region from $1.244 \pm 0.09 \mathrm{Pg} \mathrm{Cyr}^{-1}$ in the first decade of the 20th century to $1.522 \pm$ $0.09 \mathrm{Pg} \mathrm{C} \mathrm{yr}^{-1}$ in the last decade, 2001-2010, which is an increase of $0.278 \mathrm{Pg} \mathrm{Cyr}^{-1}$ for the entire time period. This is in agreement with Banger et al. (2015) who, using a single model, showed an increase of $0.23 \mathrm{Pg} \mathrm{C} \mathrm{yr}^{-1}$ for the same time period. TRENDY models show large inter-annual variations in NPP from 1.045 to $1.689 \mathrm{Pg} \mathrm{Cyr}^{-1}$ and a temporal standard deviation of $0.09 \mathrm{PgC}_{\mathrm{yr}^{-1}}$ during 1901-2010. The increase in NPP is not linear during this period, changing from 0.1 $\mathrm{PgCyr}^{-1}$ during $1901-1950$ to $0.28 \mathrm{PgC} \mathrm{Cyr}^{-1}$ during 1951-2010. A comparison of TRENDY multi-model mean NPP with estimates from previous studies for various time periods is given in table $\mathrm{S} 2$.

The mean Rh for $1901-2010$ is $1.211 \pm 0.073 \mathrm{Pg} \mathrm{C}$ $\mathrm{yr}^{-1}$ (figure 3), and it shows an increase of $0.19 \mathrm{Pg}$ ${\mathrm{C} \mathrm{yr}^{-1}}^{-1}$ through the entire time period. The NEP (Rh-NPP) for the region, from 1901 to 2010, has a multi-model mean NEP of $-0.1384 \pm$ $0.085 \mathrm{Pg} \mathrm{Cyr}^{-1}$, indicating that the NPP is larger than the $\mathrm{Rh}$ for this time period. Models such as LPJ, Lund-Potsdam-Jena general ecosystem simulator (LPJ-GUESS) and hybrid land model (HYLAND) simulate NEP with larger magnitudes (as much as $-0.25 \mathrm{PgC} \mathrm{yr}^{-1}$ ), while organising carbon and hydrology in dynamic ecosystems (ORCHIDEE) simulates a near-zero NEP. The 
(a)
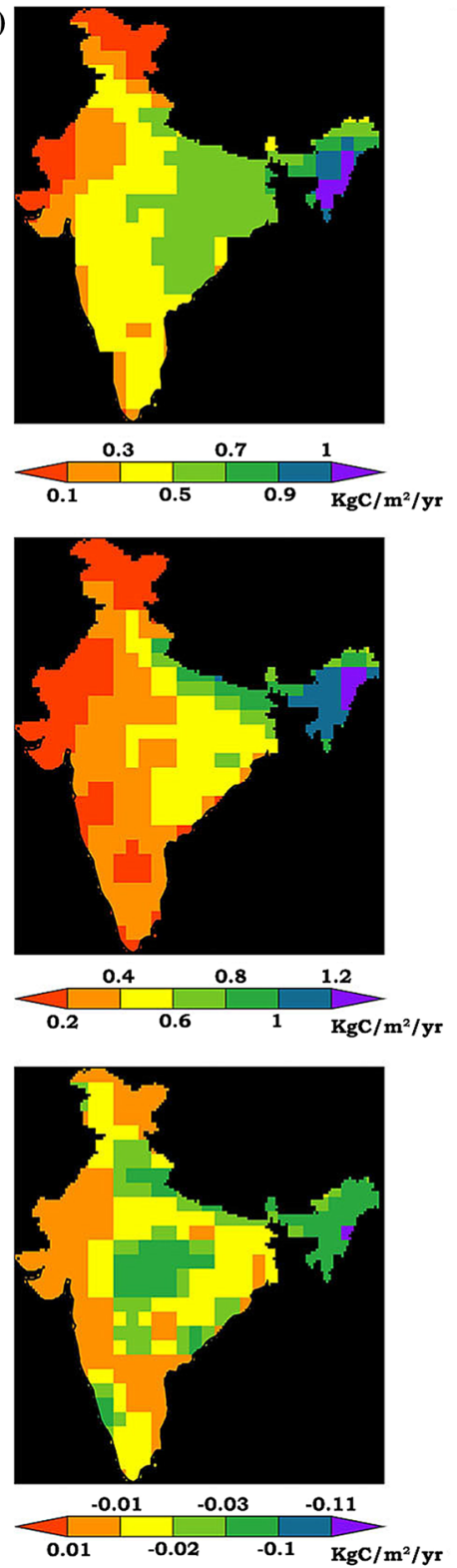

(b)
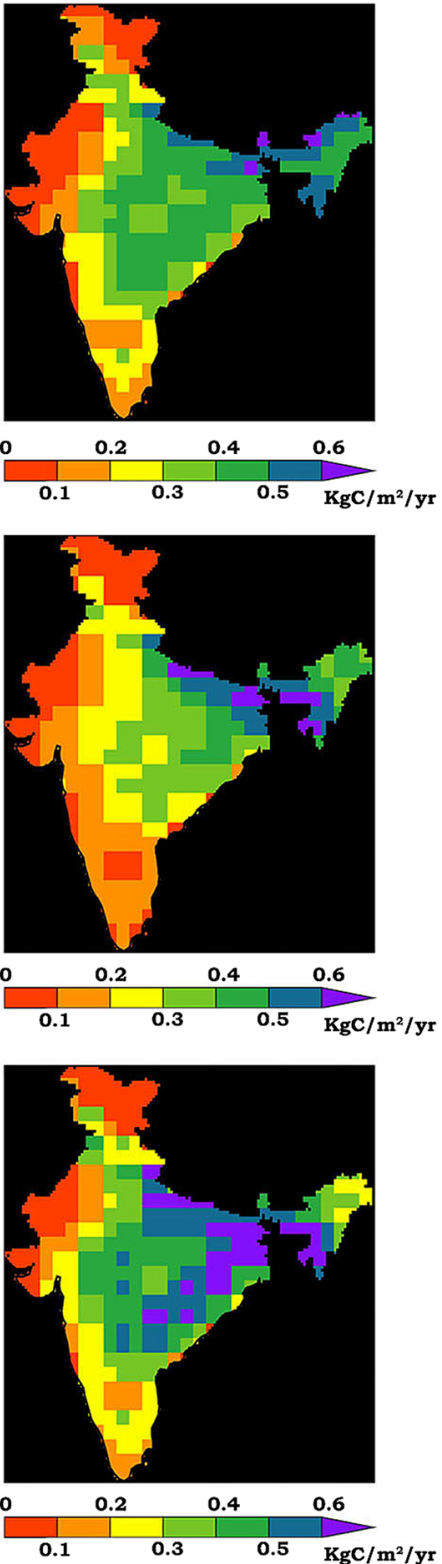

Figure 4. Spatial pattern of (a) multi-model mean (left panels) NPP, Rh and NEP averaged over 1901-2010 and (b) the corresponding temporal standard deviation (right panels).

cumulative multi-model mean TRENDY NEP for the entire period from 1901 to 2010 is $-13.78 \pm$ $0.08 \mathrm{Pg} \mathrm{C}_{\mathrm{yr}}{ }^{-1}$.

The spatial variation of the multi-model mean NPP, Rh and NEP is shown in figure 4(a). The $\mathrm{NPP}$ is as large as $\sim 1.3 \mathrm{~kg} \mathrm{C} \mathrm{m}^{-2} \mathrm{yr}^{-1}$ in the north-eastern part of the country which receives maximum rainfall and has dense forest cover and along the Himalayan belt. Similar results are reported in the satellite-based study by Bala et al. (2013), who find maximum NPP in the northeastern part of the country, although the magnitude $\left(0.8 \mathrm{~kg} \mathrm{C} \mathrm{m}^{-2} \mathrm{yr}^{-1}\right)$ is smaller than the TRENDY NPP. Minimum NPP is seen in the north-western parts of India which receives low rainfall and also in the Northern Himalayan belt which is mostly snow covered. This is in agreement with a previous study (Singh et al. 2011), using Global Production Efficiency Model (GloPEM) which reports minimum NPP of $0.5 \mathrm{~kg} \mathrm{C} \mathrm{m}^{-2} \mathrm{yr}^{-1}$ in the arid regions of Rajasthan. Bala et al. (2013) also report the lowest NPP values in these regions. Thus, spatially, NPP generally shows an increase from the drier and warmer western parts of the country to the wetter regions of the north-eastern India.

The $\mathrm{Rh}$ also follows a similar pattern as NPP. The NEP shows large negative values (NPP is 
larger than $\mathrm{Rh}$ ) in the south-western part of the country and small negative and slightly positive values of NEP in the Himalayan and north-eastern belt $\left(\sim 0.12 \mathrm{~kg} \mathrm{C} \mathrm{m}^{-2} \mathrm{yr}^{-1}\right.$ in the lower north-east). The magnitude of standard deviation in NPP varies from zero in low productivity regions of Rajasthan and Northern Himalayas and reaches values as high as $0.68 \mathrm{~kg} \mathrm{C} \mathrm{m}^{-2} \mathrm{yr}^{-1}$ in the highly productive regions of the north-east India (figure 4b). The standard deviations in Rh follow the pattern of mean Rh, but spatial pattern of standard deviation in NEP mostly follows the standard deviation in NPP (figure 4).

Figure S3 shows the long-term temporal changes in NEP along with precipitation, temperature and $\mathrm{CO}_{2}$. The trend in NEP is more negative (NPP is larger than $\mathrm{Rh}$ uptake) in the second part of the century when the atmospheric $\mathrm{CO}_{2}$ concentration and temperature also show a steeper increase compared to the first half of the time period.

\subsubsection{Seasonal variability of NPP}

The climate of India is mostly affected by the monsoon phenomenon, and India experiences four distinct seasons: south-west summer monsoon (June-September), north-east monsoon (OctoberNovember), pre-monsoon (March-May) and postmonsoon (December-February) periods. The rainfall received during south-west monsoon accounts for about $80 \%$ of the total annual rainfall of the country (Parthasarathy et al. 1995). Parts of south-eastern India receive significant rainfall during the north-east monsoon. There is a large variation in the amounts of rainfall received at different locations. The average annual rainfall ranges from $<13 \mathrm{~cm}$ in the state of Rajasthan to as much as $1087 \mathrm{~cm}$ in the state of Meghalaya (Jain Sharad and Kumar 2012).

Monthly changes in global NPP are affected by rainfall, temperature, soil moisture, surface solar radiation and the availability of nutrients. The temporal mean monthly TRENDY NPP for the seven models along with their multi-model mean, temperature and precipitation over India and global mean $\mathrm{CO}_{2}$ for the period $1981-2010$ is plotted in figure $5(\mathrm{a})$. We find that the monthly variations in multi-model mean NPP correlate well with the variations in monthly precipitation for MAM, JJA and SON (correlation of around 0.9); however, in the post-monsoon period (DJF), precipitation and NPP show a negative correlation $(-0.7)$. This is likely because irrigation drives the NPP in the winter season rather than rainfall (Raut et al. 2001). Significance of the correlations in this study has been tested by calculating the $P$-value with the cut-off of 0.05 for significance. $P$-value $<0.05$ indicates that the correlation between two variables is significant at $95 \%$ and $P$-value $>0.05$ indicates that the correlation between two variables is not significant at $95 \%$.

The seasonal means of TRENDY NPP for 19812010 are plotted in figure 5(b) which shows that the TRENDY multi-model mean NPP reaches a maximum of $0.3 \mathrm{PgCmonth}{ }^{-1}$ during the south-west monsoon period (JJA) when the region receives the maximum rainfall followed by the post-monsoon period (SON). Goroshi et al. (2014), using the satellite data-driven model CASA, also found that the NPP increases through the monsoon months of June and July and reaches a maximum in August before gradually declining in the following (SON) months. The TRENDY multi-model mean NPP reaches a minimum of $0.029 \mathrm{Pg} \mathrm{C}_{\text {month }}{ }^{-1}$ during the pre-monsoon period (MAM) which also corresponds to the lowest rainfall period for the year. Goroshi et al. (2014) and Nayak et al. (2010) also found the lowest NPP in the pre-monsoon months when the soil moisture was lowest and temperatures were high. Most observations and model-based studies on NPP over India suggest that the NPP is maximum in the post-monsoon period (Chhabra and Dadhwal 2004a; Bala et al. 2013) which is attributed to the high soil moisture content during the months of SON. As agricultural NPP accounts for $60 \%$ of the NPP over India (Panigrahy et al. 2004), this difference in the multimodel-based data and previous studies can likely be attributed to the difference in the representation of vegetation types and irrigation in TRENDY models.

\subsubsection{Trends in WUE}

The terrestrial carbon cycle is closely connected to the water cycle as water is lost to the atmosphere through stomata when carbon is fixed via photosynthesis, and hence soil water is an extremely important factor for determining the variation in productivity (Nemani et al. 2003; Ito and Inatomi 2012; Xia et al. 2015). WUE that is defined as the ratio of vegetation photosynthesis to the water released to the atmosphere by ET (Xia et al. 2015) is an indicator for the efficiency of utilisation of soil water during photosynthesis. Feng Xiahong (1999) analysed WUE based on tree-ring data and found 

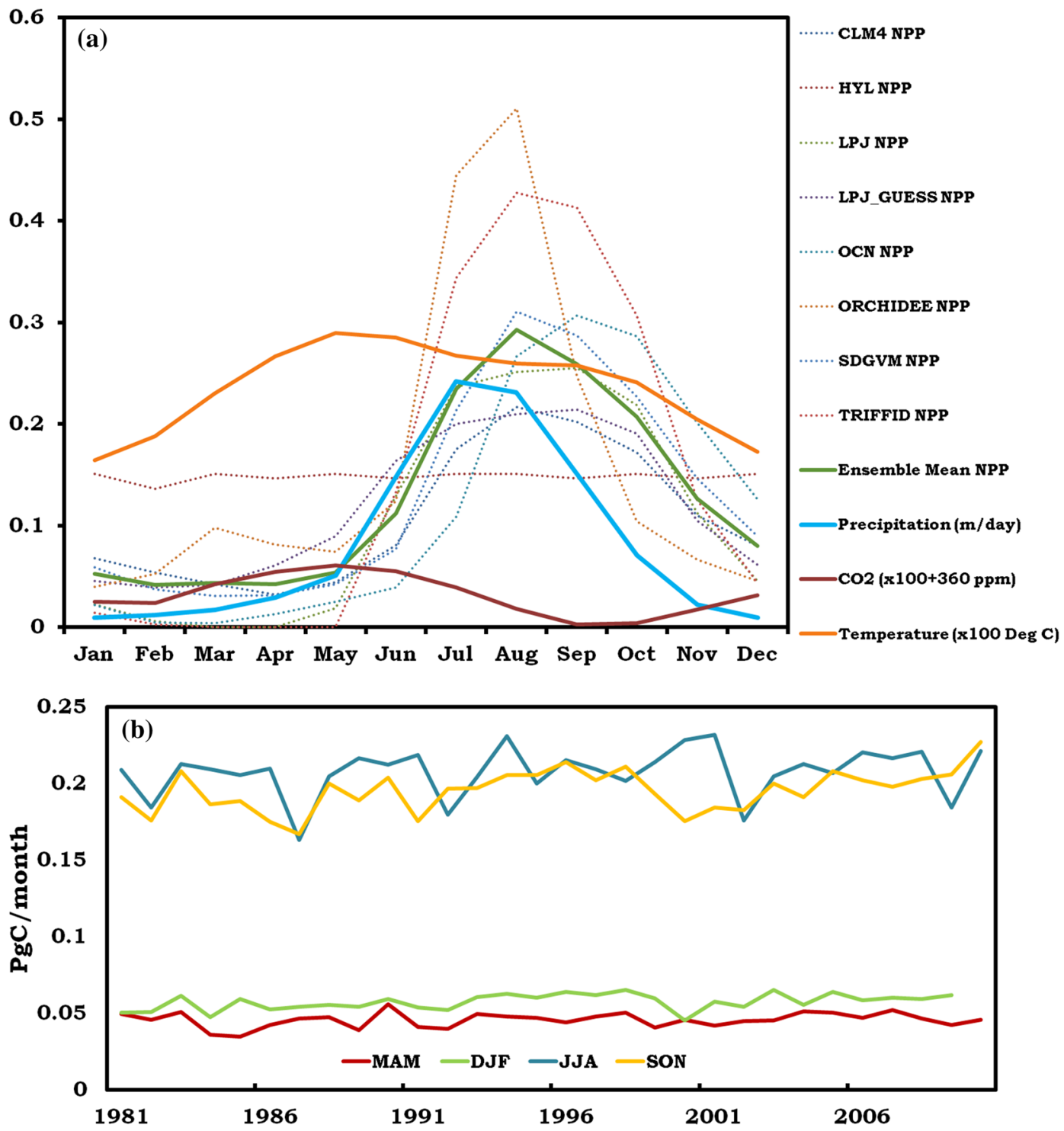

Figure 5. (a) Monthly mean values of TRENDY NPP, precipitation, temperature and $\mathrm{CO}_{2}$ averaged over 1981-2010. Some variables are scaled as shown on the right. Monthly NPP from individual models are in dotted lines. (b) Seasonal evolutions in domain averaged multi-model mean NPP for pre-monsoon (MAM), south-west monsoon (JJA), post-monsoon (SON) and winter (DJF) seasons from 1981 to 2010.

that WUE increased with increasing atmospheric $\mathrm{CO}_{2}$ concentration during the past $100-200 \mathrm{yr}$ as a result of an increase in the carbon assimilation rate and/or a decrease in the stomatal conductance. Global studies with fluxnet and satellite remote sensing-based data indicate that spatially, terrestrial WUE increases from low to high latitudes in the North America and Eurasia continents and tends to decline after reaching the peak values in the boreal regions (Tang 2014). Dekker et al. (2016) used both tree-ring data along with eddy covariance measurements to estimate the overall trend in global WUE from 1900 to 2010. They found that the global WUE increased by $\sim 50 \%$ over the 20 th century, predominantly due to rising $\mathrm{CO}_{2}$, which is also significantly more than that simulated by the latest Earth System Models from CMIP5 - an ensemble mean increase of only 14\%. Apart from the factors such as location and climatic factors that affect the productivity and in turn the WUE of the region, variations in WUE also depend on plant functional type, species composition and disturbance history (Tang 2014).

We calculate the WUE of the Indian region as the ratio of annual GPP and annual ET (Xia et al. 2015). Here, ET is defined as the total water vapour flux from the ecosystem to the atmosphere consisting of soil and canopy evaporation and plant transpiration. Of the nine models, four have ET as an output and the mean WUE of the four 
TRENDY models for the region for the $110 \mathrm{yr}$ is $1.9 \mathrm{gC}\left(\mathrm{kgH}_{2} \mathrm{O}\right)^{-1}$. During this period, WUE shows a slight increase with a trend of $0.005 \mathrm{gC}\left(\mathrm{kgH}_{2} \mathrm{O}\right)^{-1}$ $\mathrm{yr}^{-1}(\sim 25 \%$ increase over a 110 -yr period; figure S4). Previous studies on WUE in India have been mainly focused on single-plot/regional-level agricultural water use assessments for better agricultural management (Prasad et al. 2000; Sharma et al. 2010, 2015), and the regional WUE has not been investigated.

\subsection{Inter-annual variability in NEP, NPP and Rh}

\subsection{1 $\mathrm{CO}_{2}$ and climate effect}

The TRENDY NEP when only the $\mathrm{CO}_{2}$ effect (the constant climate simulation $\mathrm{S} 1$ ) is considered has an overall mean of $-0.14 \pm 0.03 \mathrm{PgC}_{\mathrm{yr}}{ }^{-1}$ which is slightly more negative than the $\mathrm{S} 2$ mean which includes the effect of climate change. The negative NEP in S1 might be attributed to $\mathrm{CO}_{2}$ fertilisation. Potential terrestrial carbon uptake by $\mathrm{CO}_{2}$ fertilisation in India has been studied by Bala et al. (2011) who found that the uptake potential by natural vegetation over India is highly sensitive to the levels of future $\mathrm{CO}_{2}$ fertilisation (the stimulation of plant photosynthesis due to rising atmospheric carbon dioxide concentrations). Schimel et al. (2015), on a global scale, suggested that up to $60 \%$ of the present-day terrestrial sink is caused by increasing atmospheric $\mathrm{CO}_{2}$. To assess the effect of climate alone in the uptake of carbon for the Indian region, we calculate the difference of the two simulations (S2 - S1). The climate effect alone shows a slightly positive mean of $0.005 \pm 0.089 \mathrm{Pg} \mathrm{C} \mathrm{yr}^{-1}$. This indicates that climate change alone is likely to cause emission of carbon from land to the atmosphere (figure S5).

\subsubsection{Climatic drivers}

The Indian region periodically experiences drought causing major famines as most of the agriculture is dependent on the monsoon rainfall (Gadgil 2003). The IMD defines a drought year as 'when the rainfall deficiency for the monsoon season of June to September for the country as a whole exceeds $10 \%$ and affects more than $20 \%$ of the country's area'. It further classifies drought into moderate and severe droughts depending upon whether the deficiency is between $26 \%$ and $50 \%$ or more than $50 \%$, respectively (IMD). The moderate and severe drought years in the period 1901-2010 were 1918, 1951,
1972, 1979, 1987 and 2009. It is noticeable that the ensemble mean NEP increases (indication of reduced carbon uptake) during a drought event (figure S6) indicating a good relationship between NEP and annual precipitation.

To further assess the relationship between regional precipitation, temperature and net carbon uptake, we analyse the TRENDY multi-model data for the last $30 \mathrm{yr}, 1981-2010$. We use correlation and linear regression to quantify the degree to which the two variables are related. It should be noted that a high value of correlation given by ' $r$ ' the coefficient of correlation, however, does not imply causation of any kind, and we caution that based on a statistical analysis like this, we cannot make robust attribution statements.

The $R^{2}$ values represent the coefficient of determination that indicates $h$ fraction of the variation in NEP could be explained by precipitation or temperature and provide a statistical measure of how close the data are to the fitted regression line.

The multi-model mean NEP from 1981 to 2010 is $-0.17 \pm 0.06 \mathrm{Pg} \mathrm{Cyr}^{-1}$. This is close to the recent study by Cervarich et al. (2016), who found NEP using TRENDY to be $-0.2 \pm 0.137 \mathrm{Pg} \mathrm{Cyr}^{-1}$ for the period 2000-2013. The TRENDY NEP and precipitation have a decreasing trend, whereas temperature has an increasing trend as shown in figure 6. All nine models show a decreasing trend in NEP (indicating increasing carbon uptake) for the same time period. The uptake by land increases with the increase in precipitation. The correlation between the multi-model mean NEP vs. precipitation and temperature is $-0.76(P$-value $<0.05)$ and $0.362(P$-value $>0.05)$, respectively. The corresponding $R^{2}$ values are 0.5713 and 0.1312 (figure S7). This implies that according to the TRENDY model ensemble, precipitation has a significant stronger control on NEP, and the increase in NEP or increase in the flux of carbon in the atmosphere is associated with the decrease in precipitation. However, the correlation between NEP and temperature is not significant.

The multi-model mean NPP shows an increasing trend as shown in figure 6 for the period 19812010. The multi-model mean NPP for the $30-y r$ period is $1.54 \pm 0.086 \mathrm{Pg} \mathrm{Cyr}^{-1}$. The correlation of TRENDY NPP with precipitation and temperature is $0.771(P$-value $<0.05)$ and -0.017 $(P$-value $>0.05)$, respectively, with $R^{2}$ values of 0.594 and 0.0003 (figure S8). This indicates that the trends and variability in NPP are also significant and strongly associated with changes in 

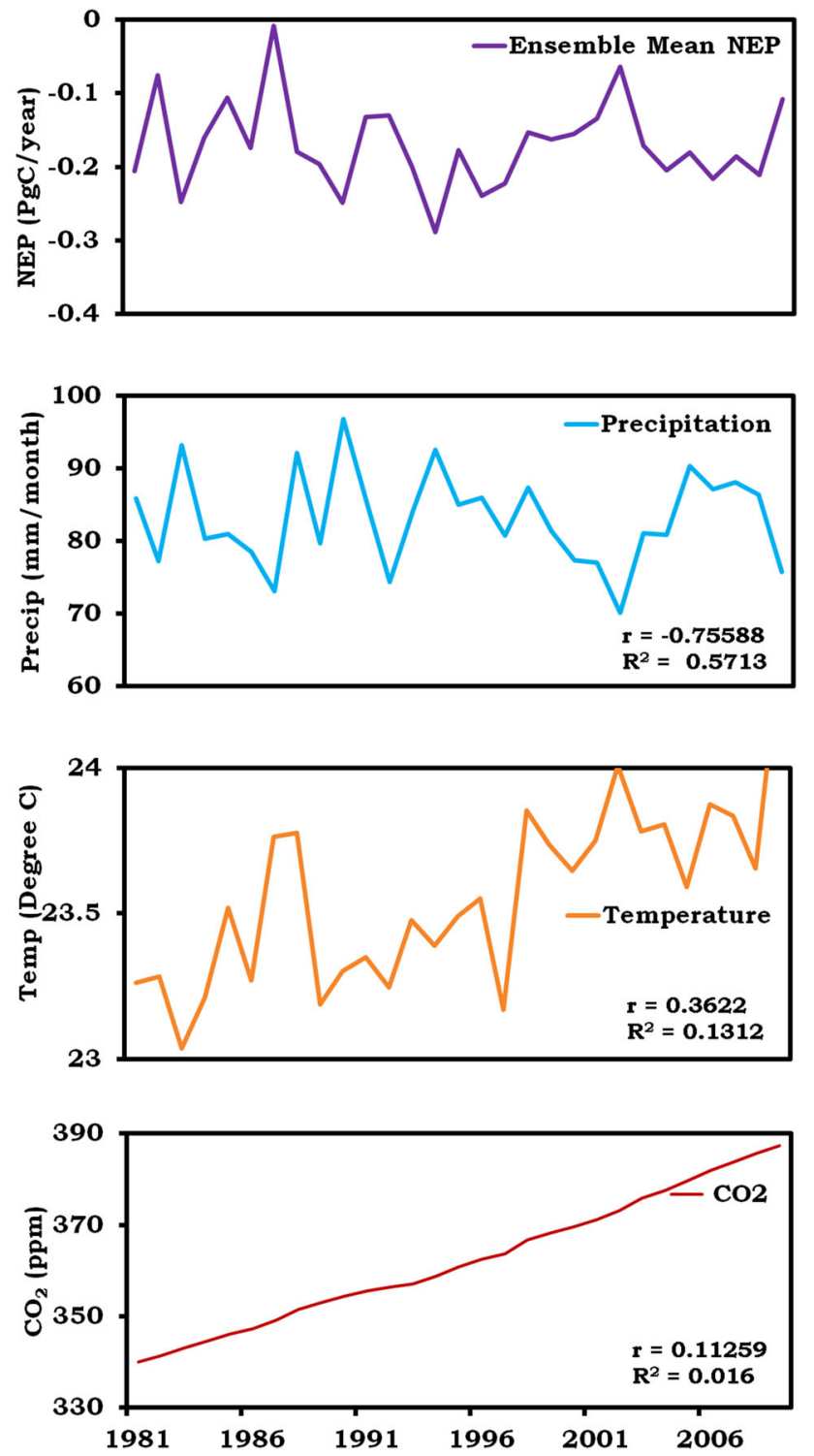

Figure 6. The temporal evolution of annual ensemble mean NEP, precipitation, temperature and $\mathrm{CO}_{2}$ from 1981 to 2010. The coefficient of correlation $(r)$ of NEP with precipitation, temperature and $\mathrm{CO}_{2}$ and the corresponding $R^{2}$ values are indicated on the bottom right corner of the plots.

precipitation. As before, the correlation between NPP and temperature is not significant.

To isolate the correlation between inter-annual variability of NEP and NPP with the inter-annual variability in temperature and precipitation, the trend and mean are removed from the time series of all the variables. We found that the inter-annual variability of NEP has a significant correlation of - $0.763(P$-value $<0.05)$ and $0.61(P$-value $<0.05)$ with precipitation and temperature, respectively (figure S9). The corresponding $R^{2}$ values are 0.582 and 0.371 , respectively. This suggests that the inter-annual variability of TRENDY multi-model carbon flux to the atmosphere is sensitive to the variability in precipitation and is only moderately affected by the variability in temperature as well. These conclusions are also valid for NPP. The inter-annual changes in NPP are strongly correlated with the changes in precipitation and only moderately with the changes in temperature. The correlation and $R^{2}$ values for detrended NPP vs. detrended precipitation and temperature are 0.867 ( $P$-value $<0.05), 0.7533(P$-value $<0.05)$, -0.4855 and 0.235 , respectively (figure S10).

\subsection{Remote influences of ENSO and IOD on NPP and NEP}

The effect of large-scale climatic phenomenon such as ENSO on the Indian climate has been studied extensively in the last few years (Gadgil 2003; Kumar et al. 2006), and a strong correlation between El Niño and drought years in India is well established now. For instance, the drought of 2002 coincided with a strong El Niño and Indian monsoon rainfall decreased by more than $19 \%$ from its long period average (Saini and Gulati 2014). Furthermore, since 1980, all the six droughts in India were in El Niño years, but it should be also noted that not all El Niño years lead to drought in the country. In this paper, we analyse the influence of ENSO on the Indian region land carbon flux.

Nemani et al. (2003) used both climatic data and satellite observations of vegetation activity and found that globally NPP declined during major El Niño events with corresponding increases in global $\mathrm{CO}_{2}$ growth rate. To assess the influence of ENSO on the Indian land carbon flux, we estimate the temporal correlation of the multi-model mean NEP with the MEI. We find a low correlation of $0.31(P$-value $>0.05)$ with an $R^{2}$ value of only 0.0971 (figures 7 and S7). The detrended MEI and detrended multi-model mean NEP also have a low temporal correlation of $0.146(P$-value $>0.05$ ) and $R^{2}$ value of 0.02 (figure $\mathrm{S} 9$ ). The NPP shows a slightly negative significant temporal correlation with the MEI $(-0.316(P$-value $<0.05), R^{2}=0.1$, figure S8), and the inter-annual variability (detrended values) of NPP has a negative correlation of $-0.195\left(P\right.$-value $>0.05, R^{2}=$ 0.005; figure S10) with ENSO. However, isolating the ENSO years and finding the correlation with NEP of India, we find a high positive correlation of 0.69 ( $P$-value $\left.>0.05, R^{2}=0.48\right)$ suggesting that the intensity of ENSO may have an influence over the magnitude of NEP anomaly in India 


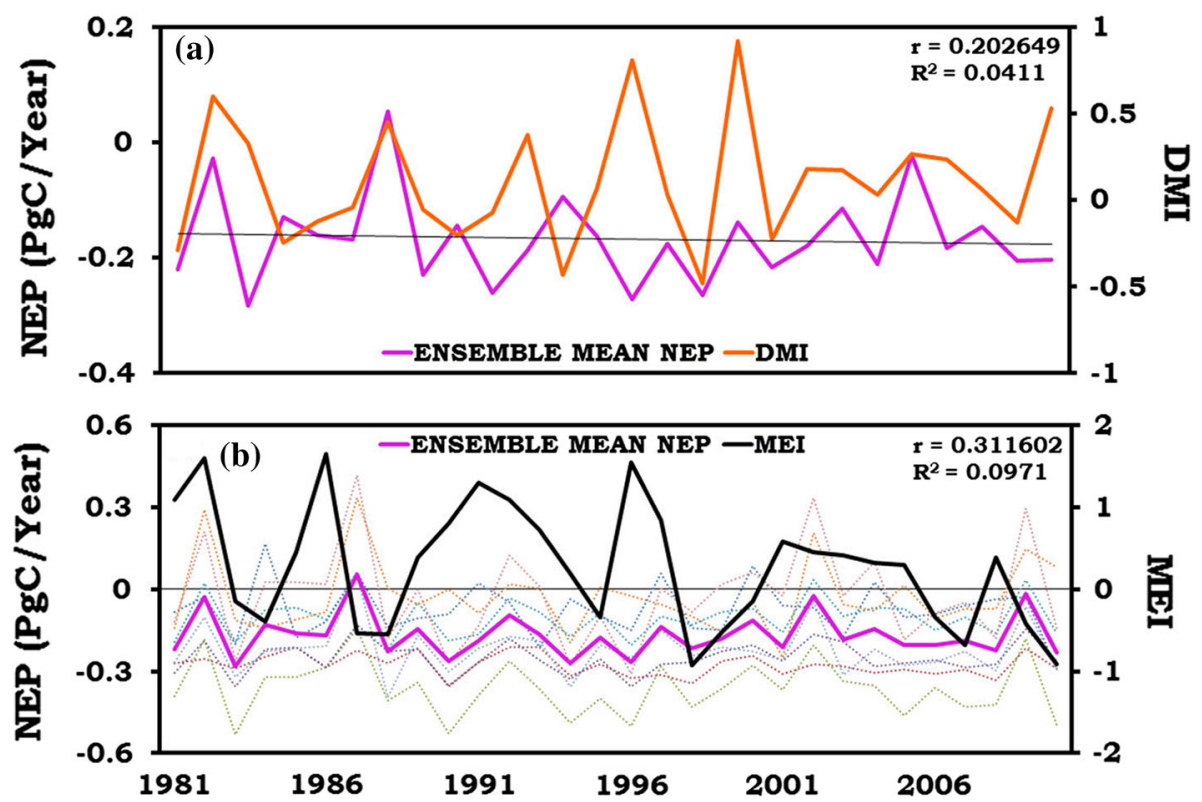

Figure 7. The temporal evolution of (a) NEP (purple) and dipole mode index (DMI in orange) and (b) NEP and multivariate ENSO index (black) for the period 1981 to 2010. The NEP from individual models is shown as dotted lines. The coefficient of correlation $(r)$ and the corresponding $R^{2}$ values are indicated on the top right corner of the plots.

in ENSO years. Furthermore, when correlation of NPP with only the ENSO years is calculated, we find a larger negative correlation of -0.73 ( $P$-value $\left.>0.05, R^{2}=0.32\right)$. This shows that the productivity of the Indian region is smaller during stronger ENSO years than weaker ENSO years indicating an influence of warming in the Pacific Ocean on the NPP anomaly of the region. Further investigation is, however, needed to make a robust attribution statement.

The IOD is another large-scale phenomenon, affecting Indian climate and occurs closer to the Indian continent (Saji et al. 1999). The NEP shows lower temporal correlation of $0.202(P$-value $>0.05)$ and $R^{2}$ of 0.04 with the DMI, and the inter-annual variability of NEP has negligible correlation of $0.02(P$-value $>0.05)$ with the variability of DMI. The correlation with the trend in NPP and DMI is -0.008 ( $P$-value $>0.05)$ and the detrended NPP has a correlation of -0.07 ( $P$-value $>0.05)$ with detrended DMI. As the correlations are not significant, we infer that the IOD and the warming in the western tropical Indian Ocean have weak or negligible influence on NPP and NEP of the Indian region. Our investigation of the relationship of these remote climatic events with the NPP and NEP variations over India is based on TRENDY models, which are stand-alone models and they do not include feedbacks from the atmosphere and oceans.

\subsection{An estimate of NEE}

Human-induced changes to land surface could also play an important part in the uptake of carbon in the region. As described in section 2, NEE is defined as the total sum of NEP, fire flux and LUF.

Fire is a key driver affecting earth system processes including the carbon cycle, as it is an important source of $\mathrm{CO}_{2}$ emissions (Marlon et al. 2009). In India, forest fires are a major cause of degradation of forests. Agricultural biomass burning is also a large contributor to the emission of $\mathrm{CO}_{2}$ to the atmosphere (Thokchom and Yadava 2016). The carbon flux to the atmosphere from fires is output as fire flux in some models incorporated with a fire module. Of the nine TRENDY models, four include the fire module, and the fire flux is obtained from these four models used here (figure S11). The cumulative multi-model TRENDY NEP for the entire period from 1901 to 2010 is $-15.22 \pm$ $0.08 \mathrm{Pg} \mathrm{C}$ (figure 8). The corresponding cumulative fire flux for the same period is $9.61 \pm 0.014 \mathrm{PgC}$ (figure 8).

The net flux from land use changes is the most uncertain term in the carbon budget because of uncertainties in the estimates of rates of deforestation and reforestation and the density of carbon in the lands undergoing change (Houghton et al. 2012). However, in India, the uncertainty in land use change estimates has reduced considerably 


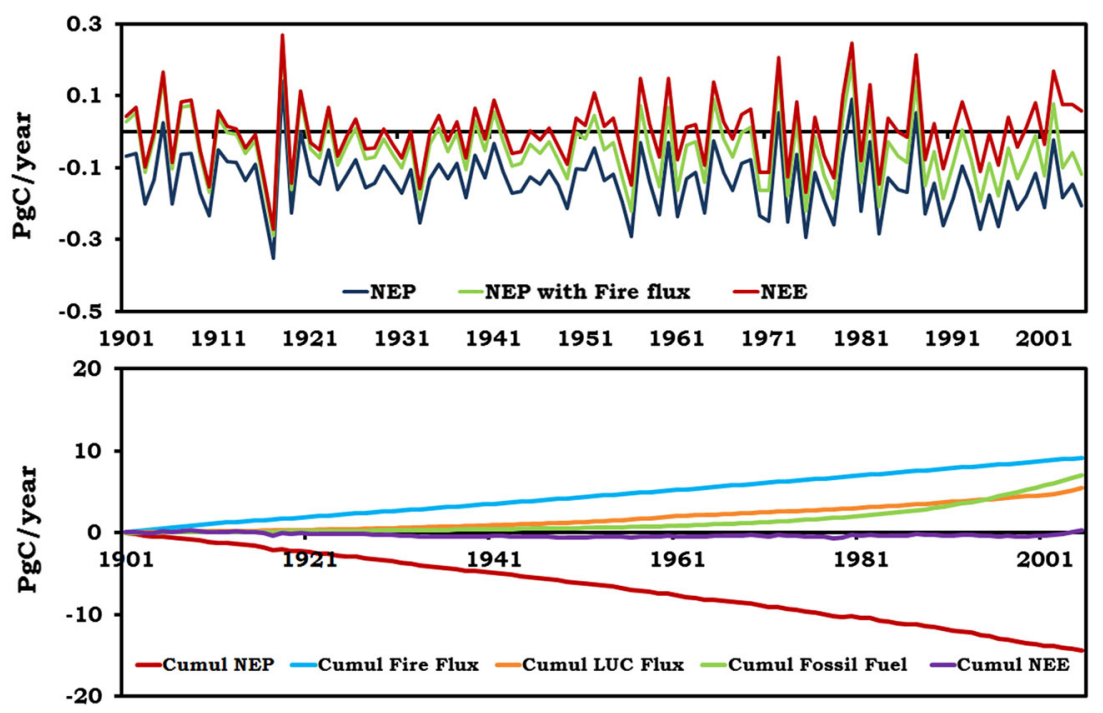

Figure 8. The top panel shows the long-term domain averaged temporal evolution (1901-2010) of annual multi-model mean NEP (blue), summation of NEP and fire flux (red) and NEE (green) calculated as a sum of NEP, fire and land use change flux. The bottom panel shows the cumulative fluxes: cumulative NEP (red), cumulative fire flux (blue), cumulative LUC flux (orange), cumulative emissions from fossil fuel and cement production (green) and cumulative NEE (purple). Fluxes are positive when they are directed from land to the atmosphere. The evolution of NEE shows that the Indian region has been neither a strong source nor a sink for carbon during the entire period.

in the recent years because of the advances in high-resolution remote sensing for the mapping of land use. In India, large fluxes result from the conversion of forest land to cropland and wastelands (Ravindranath et al. 1997; Kaul et al. 2009). Since the land use is kept constant in the TRENDY models for both S1 and S2 simulations, we use land use change flux from a CESM historical simulation where CLM4 is the land component (Devaraju et al. 2015, table S10). There are very few studies in India on the estimation of the net carbon flux due to land use and land cover change, and the studies that are available are for a particular year or two, and hence, there is an inherent uncertainty in using these global data sets for the estimation of land use change flux over India. The flux estimates in these studies vary from emissions of around $0.67 \mathrm{Tg} \mathrm{C} \mathrm{yr}^{-1}$ to a positive sink of $5 \mathrm{Tg} \mathrm{C} \mathrm{yr}^{-1}$. Ravindranath et al. (1997) estimated a marginal net sequestration of $5 \mathrm{Tg} \mathrm{C}$ by the forests in India for the reference year 1986. Our estimate of average land use land cover change flux over India from CLM4 for the $110 \mathrm{yr}$ is $0.04 \mathrm{Pg} \mathrm{Cyr}^{-1}$ which is well within the range of the previous estimates. The cumulative land use flux for India from CLM4 during 1901-2010 is $5.94 \pm 0.06 \mathrm{PgC}$ (figure 8).

The NEE for India for the historical period is obtained by combining the values of NEP, fire flux and land use fluxes. We find that for the entire period from 1901 to 2010, the average NEE for
India is $0.005 \pm 0.1 \mathrm{Pg} \mathrm{Cyr}^{-1}$ and the cumulative $\mathrm{NEE}$ is $0.613 \pm 0.1 \mathrm{PgC}$. Therefore, our multimodel-based estimate of NEE shows the Indian terrestrial ecosystem to be neither a strong source nor a significant sink during the historical period. However, further investigations using more observational data and a set of comprehensive coupled models that include several feedbacks between land, atmosphere, ocean and the cryosphere are needed to determine the robustness of the results from this study.

Country-wise anthropogenic carbon emissions from fossil fuel combustion, including gas flaring and cement production, based primarily on energy consumption data, specifically data on hydrocarbon fuels, are collated and archived by the Carbon Dioxide Information Analysis Center (CDIAC; Boden et al. 2016). According to these data, India has cumulatively emitted $9.13 \mathrm{Pg} \mathrm{C}$ from fossil fuel burning and cement production with an average emission of $0.08 \mathrm{PgC}_{\mathrm{yr}}{ }^{-1}$. Thus, when fossil fuel emissions are considered, the Indian region has been a net source of carbon from 1901 to 2010 (9.14 Pg C).

\section{Discussions and conclusion}

We use nine models from the TRENDY multimodel data set to analyse the trends in carbon 
uptake over India in the past 110 yr (1901-2010). The TRENDY ensemble mean results compare well with the observational data set for the Indian region. Important carbon cycle variables such as NPP, soil carbon and ET have a spatial correlation of more than 0.5 with observational data sets indicating fair confidence in the results for the region. The models used in our study have been validated for other regions of the world (as specified in the fourth column of table S1) but have not been validated over India using ground-based observational data. The absolute value of NPP obtained from previous studies shows a large range, and hence, we recognise the large uncertainties in model-simulated values. However, we emphasise that our study is focused on the long-term trends and variability of terrestrial carbon variables, and hence, implicitly, this study is focused on the trends and variability of anomalies relative to a mean. Therefore, it is unlikely that our results would be affected by the uncertainty in absolute value (bias) of the terrestrial carbon variables simulated by these models. Furthermore, there is currently a lack of publicly accessible ground-based observational data over India (Nayak et al. 2016). It is likely that the inadequate validation (lack of site-level validation) in this paper could contribute to large uncertainty in the results and conclusions reached. The evaluation of TRENDY models using ground-based data over India would be the subject of a future paper.

The TRENDY multi-model mean NPP for the entire period of $110 \mathrm{yr}$ shows an increase of $22.4 \%$ $\left(0.278 \mathrm{Pg} \mathrm{Cyr}^{-1}\right)$. The increase in NPP is higher in the second part of the century, which is likely due to the accelerated increase in the atmospheric $\mathrm{CO}_{2}$. Heterotrophic respiration also shows an increasing trend of $0.19 \mathrm{Pg} \mathrm{Cyr}^{-1}(19.96 \%)$ throughout the entire time period. Thus, NEP for India is negative (carbon flux is defined positive when it is directed from land to the atmosphere), and its magnitude increases marginally from $0.12 \mathrm{PgCyr}^{-1}$ in the first decade to $0.19 \mathrm{Pg} \mathrm{Cyr}^{-1}$ in the last decade of 1901-2010 with higher inter-annual variations in the second part of the time period. When additional fluxes from land use change and fire losses are added to the NEP to calculate NEE, an average NEE of $0.005 \pm 0.1 \mathrm{Pg} \mathrm{C} \mathrm{yr}^{-1}$ and cumulative NEE of $0.613 \pm 0.1 \mathrm{Pg} \mathrm{C}$ are estimated. These estimates indicate that the region is neither a strong source nor a significant sink for the period 1901-2010. When the emissions from fossil fuel combustion and cement production are included, the Indian region has been a source of carbon from 1901 to 2010 with a cumulative sum of $9.14 \mathrm{Pg} \mathrm{C}$ released to the atmosphere.

Spatially, NPP generally shows an increase from drier and warmer west parts of the country to wetter regions of the north-eastern India. Seasonal changes in NPP for the period from 1981 to 2010 show that the NPP is maximum in JJA and minimum in the Indian summer months of MAM. This is attributed to a strong correlation of model mean NPP with precipitation. The WUE for the region for $110 \mathrm{yr}$ is $1.9 \mathrm{gC}\left(\mathrm{kgH}_{2} \mathrm{O}\right)^{-1}$, and it shows an increase of $25.4 \%$ over the period.

Among the climatic drivers, precipitation is highly negatively correlated with NEP $(-0.76$; carbon fluxes from land to atmosphere are smaller when precipitation is larger), whereas changes in temperature and atmospheric $\mathrm{CO}_{2}$ do not show much correlation with NEP for the period 19812010. Remote influences from ENSO and IOD on the land carbon uptake are weak as suggested by the low correlation between them.

In this study, model structural errors, simplified representation for vegetation types and structure, parameterisation of physical and biological processes, uncertainties in input data sets, etc., can cause uncertainties in the estimate of carbon fluxes and stocks (Kicklighter et al. 1999). We recognise that the terrestrial carbon cycle models need to improve both process representations and ecosystem structure modelling to better quantify the regional carbon cycle and its trends. However, the aspect of improvement in model parameterisation and sensitivity is not discussed in detail in our study.

India is a subcontinent with large diversity in soil types, vegetation types and land use patterns are as small as fine scale of $100 \mathrm{~m}$ or less (Joshi et al. 2006). However, the resolution of the model runs used here varies from $0.5^{\circ} \times 0.5^{\circ}$ to $3.75^{\circ} \times 2.5^{\circ}$. This resolution for Indian region is coarse and might be a source of uncertainty in the results as the changes that occur from state to state in India are not well represented at this resolution.

Moreover, only two models have explicit representation of the nitrogen cycle. In most of the TRENDY models, the interaction between the various constraining nutrients such as nitrogen, phosphorus, etc., are not incorporated. All of the TRENDY models are stand-alone land surface models, and thus, the critical feedbacks between land surface and the atmosphere and ocean are 
missing (Sokolov et al. 2008; Gregory et al. 2009; Zaehle and Dalmonech 2011).

Nevertheless, this paper is the first to perform a long-term historical analysis of land carbon cycle in the Indian region, and hence, the results of this study are novel and important. However, investigations using data from other multi-model inter-comparison projects such as CMIP5 are needed to assess the robustness of the results discussed in this study. More extensive observational networks are also necessary for better validation of the model-based results and a comprehensive understanding of the trends and variability in regional carbon cycle in India. Further work with TRENDY models could use the newly available version of the data set, TRENDY v2, and the current work can be validated with the results from the new version.

\section{Acknowledgements}

We thank the consortium of TRENDY modellers, S Sitch, P Friedlingstein, N Gruber, S D Jones, G Murray-Tortarolo, A Ahlström, S C Doney, H Graven, C Heinze, C Huntingford, S Levis, P E Levy, M Lomas, B Poulter, N Viovy, S Zaehle, N Zeng, A Arneth, G Bonan, L Bopp, J G Canadell, F Chevallier, P Ciais, R Ellis, M Gloor, P Peylin, S L Piao, C Le Quéré, B Smith, Z Zhu and R Myneni, for providing us access to the TRENDY model outputs. We thank G Murray-Tortarolo for providing us links to the TRENDY model data set. We also thank Ms Indu K Murthy for her valuable suggestions and proofreading of the paper. A S Rao acknowledges the scholarship provided by the Indian Institute of Science.

\section{References}

Bala G, Gopalakrishnan R, Jayaraman M, Nemani R and Ravindranath N H $2011 \mathrm{CO}_{2}$-fertilization and potential future terrestrial carbon uptake in India; Mitig. Adapt. Strat. Gl. 16 143-160.

Bala G, Joshi J, Chaturvedi R K, Gangamani H V, Hashimoto H and Nemani R 2013 Trends and variability of AVHRR-derived NPP in India; Remote Sens. 5 810829, https://doi.org/10.3390/rs5020810.

Banger K, Tian H, Tao B, Ren W, Pan S, Dangal S and Yang J 2015 Terrestrial net primary productivity in India during 1901-2010: Contributions from multiple environmental changes; Clim. Change Springer, https://doi.org/ 10.1007/s10584-015-1448-5.

Basha G, Kishore P, Venkat Ratnam M, Jayaraman A, Kouchak A A, Ouarda T B M J and Velicogna I 2017 Historical and projected surface temperature over India during the 20th and 21st century; Sci. Rep. 7 2987, https://doi.org/10.1038/s41598-017-02130-3.

Beer C, Reichstein M and Tomelleri E et al. 2010 Terrestrial gross carbon dioxide uptake: Global distribution and covariation with climate; Science 329 834-838, https:// doi.org/10.1126/science.1184984.

Boden T A, Marland G and Andres R J 2016 Global regional and national fossil-fuel $\mathrm{CO}_{2}$ emissions; Report by Carbon Dioxide Information Analysis Center, Oak Ridge National Laboratory, US Department of Energy, Oak Ridge, TN, USA, https://doi.org/10.3334/CDIAC/00001_V2016.

Bolin B, Sukumar R, Ciais P, Cramer W, Jarvis P, Kheshgi H, Nobre C, Semenov S and Steffen W 2000 Global perspective; In: IPCC land use land-use change and forestry a special report of the IPCC (eds) Watson $\mathrm{R} \mathrm{T}$, Noble I $\mathrm{R}$, Bolin B, Ravindranath N H, Verardo D J and Dokken D J, Cambridge University Press, pp. 23-51.

Brown S et al. 1993 Geographical distributions of carbon in biomass and soils of tropical Asian forests; Geocarto Int. 4 45-59.

Canadell J G 2011 An international effort to quantify regional carbon fluxes; Eos: Earth Space Sci. News 92(10) 81-88.

Cervarich M, Shu S, Jain A K, Arneth A, Canadell J, Friedlingstein P, Houghton R A, Kato E, Koven C, Patra P, Poulter B, Sitch S, Stocker B, Viovy N, Wiltshire A and Zeng N 2016 The terrestrial carbon budget of south and Southeast Asia; Environ. Res. Lett. 11, https://doi. org/10.1088/1748-9326/11/10/105006.

Chhabra A and Dadhwal V K 2004a Estimating terrestrial net primary productivity over India using satellite data; Curr. Sci. 86(2) 269-271.

Chhabra A and Dadhwal V K 2004b Assessment of major pools and fluxes of carbon in Indian forests; Clim. Change 64 341-360.

Cramer W et al. 1999 Comparing global models of terrestrial net primary productivity (NPP): Overview and key results; Global Change Biol. 5(S1) 1-15, https://doi.org/ 10.1046/j.1365-2486.1999.00009.x.

Dadhwal V K 2012 Assessment of Indian carbon cycle components using earth observation systems and ground inventory; ISPRS Arch. XXXIX-B8 249-254.

Dekker S C, Groenendijk M, Booth Ben B B, Huntingford C and Cox P M 2016 Spatial and temporal variations in plant water-use efficiency inferred from tree-ring eddy covariance and atmospheric observations; Earth Syst. Dyn. 7 525-533, https://doi.org/10.5194/esd-7-525-2016.

Dentener F, Stevenson D, Ellingsen K, van Noije T, Schultz M, Amann M, Atherton C, Bell N, Bergmann D, Bey I, Bouwman L, Butler T, Cofala J, Collins B, Drevet J, Doherty R, Eickhout B, Eskes H, Fiore A, Gauss M, Hauglustaine D, Horowitz L, Isaksen I S A, Josse B, Lawrence M, Krol M, Lamarque J F, Montanaro V, Muller J F, Peuch V H, Pitari G, Pyle J, Rast S, Rodriguez J, Sanderson M, Savage N H, Shindell D, Strahan S, Szopa S, Sudo K, Van Dingenen R, Wild O and Zeng G 2006 The global atmospheric environment for the next generation; Environ. Sci. Technol. 40 3586-3594, https://doi. org/10.1021/es0523845.

Devaraju N, Bala G, Caldeira K and Nemani R 2015 A model based investigation of the relative importance of $\mathrm{CO}_{2}$ fertilization climate warming nitrogen deposition and land 
use change on the global terrestrial carbon uptake in the historical period; Clim. Dyn., https://doi.org/10.1007/ s00382-015-2830-8.

Feng Xiahong 1999 Trends in intrinsic water-use efficiency of natural trees for the past 100-200 years: A response to atmospheric $\mathrm{CO}_{2}$ concentration; Geochim. Cosmochim. Acta 63(13/14) 1891-1903, https://doi. org/10.1016/S0016-7037(99)00088-5.

Gadgil S 2003 The Indian monsoon and its variability; Annu. Rev. Earth Planet. Sci. 31 429-467.

Gebremichael M and Barros A P 2006 Evaluation of MODIS gross primary productivity (GPP) in tropical monsoon regions; Remote Sens. Environ. 100 150-166.

Goroshi S, Singh R P, Pradhan R and Singh Parihar J 2014 Assessment of net primary productivity over India using Indian geostationary satellite (INSAT-3A) data; ISPRS Arch. XL-8.

Gregory J M, Jones C D, Cadule P and Friedlingstein P 2009 Quantifying carbon cycle feedbacks; J. Clim. 22 52325250, https://doi.org/10.1175/2009JCLI2949.1.

Haverd V, Raupach M R, Briggs P R, Canadell J G, Davis S J, Law R M, Meyer C P, Peters G P, Pickett-Heaps C and Sherman B 2013 The Australian terrestrial carbon budget; Biogeosci. 10 851-869, https://doi.org/10.5194/ bg-10-851-2013.

Heinsch F A and Zhao M et al. 2006 Evaluation of remote sensing based terrestrial productivity from MODIS using regional tower eddy flux network observations; IEEE Trans. Geosci. Remote Sens. 44 1908-1925.

Hingane L S 1991 Some aspects of carbon dioxide exchange between atmosphere and Indian plant biota; Clim. Change 18 425-435.

Houghton R A et al. 2012 Carbon emissions from land use and land-cover change, Biogeosci. 9(12) 5125-5142, https://doi.org/10.5194/bg-9-5125-2012.

ISFR 2015 India State of Forest Report, http://fsi.nic.in/ isfr-2015/isfr-2015-executive-summary.pdf.

Ito A and Inatomi M 2012 Water-use efficiency of the terrestrial biosphere: A model analysis focusing on interactions between the global carbon and water cycles; Am. Meterol. Soc. 13 681-694, https://doi.org/10.1175/ JHM-D-10-050341.

Jain Sharad K and Kumar V 2012 Trend analysis of rainfall and temperature data for India; Curr. Sci. 102(1) 37-49.

Joshi P K, Roy P S, Singh S, Agrawal S and Yadav D 2006 Vegetation cover mapping in India using multi-temporal IRS wide field sensor (WiFS) data; Remote Sens. Environ. 103 190-202, https://doi.org/10.1016/j.rse.2006.04.010.

Kaul M, Dadhwal V K and Mohren G M J 2009 Land use change and net $\mathrm{C}$ flux in Indian forests; For. Ecol. Manag. $258 \quad$ 100-108, https://doi.org/10.1016/ jforeco200903049.

Kicklighter D W, Bondeau A, Schloss A L, Kaduk J, Mcguire A D and the participants of the Potsdam NPP model intercomparison 1999 Comparing global models of terrestrial net primary productivity (NPP): Global pattern and differentiation by major biomes; Glob. Change Biol. 5(suppl 1) 16-24.

Kumar K K, Rajagopalan B, Hoerling M, Bates G and Cane M 2006 Unraveling the mystery of Indian monsoon failure during El Nino; Science 314 115-119. https://doi.org/10. 1126/science.1131152.
Le Quere C, Andres R J and Boden T et al. 2013 The global carbon budget 1959-2011; Earth Syst. Sci. Data 5 165185, https://doi.org/10.5194/essd-5-165-2013.

Maignan F, Breon F M, Chevallier F, Viovy N, Ciais P, Garrec C, Trules J and Mancip M 2011 Evaluation of a global vegetation model using time series of satellite vegetation indices; Geosci. Model Dev. 4 1103-1114, https://doi.org/ 10.5194/gmd-4-1103-2011.

Marlon J R et al. 2009 Wildfire responses to abrupt climate change in North America; Proc. Natl. Acad. Sci. 106(8), https://doi.org/10.1073/pnas.0808212106.

Moeletsi M E and Walker S 2012 Evaluation of NASA satellite and modelled temperature data for simulating maize water requirement satisfaction index in the free state province of South Africa; Phys. Chem. Earth. 50-52 157164, https://doi.org/10.1016/j.pce.2012.08.012.

NATCOM2 Report 2012 Second National Communication to the United Nations Framework Convention on Climate Change India, Ministry of Environment \& Forests Government of India, http://unfccc.int/resource/docs/natc/ indnc2.pdf

Nayak R K, Patel N R and Dadhwal V K 2010 Estimation and analysis of terrestrial net primary productivity over India by remote-sensing-driven terrestrial biosphere model; Environ. Monit. Assess. 170 195-213. https://doi. org/10.1007/s10661-009-1226-9.

Nayak R K, Dadhwal V K, Patel N R and Dutt C B S 2011 Inter-annual variability of net ecosystem productivity over India; ISPRS Arch. XXXVIII-8/W20.

Nayak R K, Patel N R and Dadhwal V K 2013 Inter-annual variability and climate control of terrestrial net primary productivity over India; Int. J. Climatol. 33 132-142, https://doi.org/10.1002/joc.3414.

Nayak R K, Patel N R and Dadhwal V K 2015 Spatiotemporal variability of net ecosystem productivity over India and its relationship to climatic variables; Environ. Earth Sci. 74 1743-1753, https://doi.org/10.1007/ s12665-015-4182-4.

Nayak R K et al. 2016 Terrestrial net primary productivity and net ecosystem productivity over India; Report by National Remote Sensing Centre, Balanagar, Hyderabad.

Nemani R R, Keeling C D, Hashimoto H, Jolly J M, Piper S C, Tucker C J, Myneni R B and Running S W 2003 Climate-driven increases in Global terrestrial net primary production from 1982 to 1999; Sci. China C 300 15601563.

Oleson K W et al. 2010 Technical description of version 4.0 of the community land model (CLM); Report by Climate and Global Dynamics Division NCAR.

Panigrahy R K, Panigrahy S and Parihar J S 2004 Spatiotemporal pattern of Agro Ecosystem Net Primary Productivity of India: A preliminary analysis using SPOT VGT data, Indian Space Research Organization Report, Commission IV, WG IV/10.

Parthasarathy B, Munot A A and Kothawale D R 1995 All India monthly and seasonal rainfall series: 1871-1993; Theor. Appl. Climatol. 49 217-224.

Patra P K, Canadell J G and Houghton R A et al. 2013 The carbon budget of South Asia; Biogeosciences 10 513-527. https://doi.org/10.5194/bg-10-513-2013.

Piao S, Sitch S, Ciais P, Friedlingstein P, Peylin P, Wang X, Ahlstrom A, Anav A, Canadell J G, Huntingford C, 
Jung M, Levis S, Levy P E, Lomas M R, Lu M, Luo Y, Myneni R B, Poulter B, Wang T, Viovy N, Zaehle S and Zeng N 2013 Evaluation of terrestrial carbon cycle models for their sensitivity to climate variability and the observed rise in atmospheric $\mathrm{CO} 2$ abundance; Glob. Change Biol., https://doi.org/10.1111/gcb.12187.

Prakash S et al. 2015 Seasonal intercomparison of observational rainfall datasets over India during the southwest monsoon season; Int. J. Climatol. 35(9) 2326-2338. https://doi.org/10.1002/joc.4129.

Prasad M R, Singh A P and Singh B 2000 Yield water-use efficiency and potassium uptake by summer mungbean as affected by various levels of potassium and moisture stress; J. Integrated Soc. Sci. 48(4) 827-828.

Raut S, Sarma K S S and Das D K 2001 Evaluation of irrigation management in a canal command area based on agrometeorology and remote sensing; J. Ind. Soc. Remote Sens. 29(4) 225-228.

Ravindranath N H, Somashekhar B S and Gadgil M 1997 Carbon flow in Indian forests; Clim. Change 35 297-320.

Saini S and Gulati A 2014 El Niño and Indian Droughts A scoping exercise working paper 276; Report by Indian Council for Research on International Economic Relations, http://www.icrier.org/pdf/working_paper_276.pdf.

Saji N H, Goswami B N, Vinayachandran P N and Yamagata T 1999 A dipole mode in the tropical Indian ocean; Nature 401.

Schimel D S, House J I, Hibbard K A, Bousquet P and Ciais $\mathrm{P}$ et al. 2001 Recent patterns and mechanisms of carbon exchange by terrestrial ecosystems; Nature 414 169-172.

Schimel D, Stephens B B and Fisher J B 2015 Effect of increasing $\mathrm{CO}_{2}$ on the terrestrial carbon cycle; Proc. Nat. Acad. Sci. 112(2) 436-441, https://doi.org/10.1073/ pnas.1407302112.

Schulze E-D, Wirth C and Heimann M 2000 Climate change: Managing forests after Kyoto; Science 289 2058-2059, https://doi.org/10.1126/science.289.5487.2058.

Sharma B R, Rao K V, Vittal K P R, Rammakrishna Y S and Amarasinghe U 2010 Estimating the potential of rainfed agriculture in India: Prospects for water productivity improvements; Agric. Water Manag. 97(1) 23-30.

Sharma B, Molden D and Cook S 2015 Water use efficiency in agriculture: Measurement current situation and trends, book chapter; In: Managing water and fertilizer for sustainable agricultural intensification (eds) Drechsel P, Heffer P, Magen H, Mikkelsen R and Wichelns D, pp. 39-64.

Singh R P, Rovshan S, Goroshi S K, Panigrahy S and Parihar J S 2011 Spatial and temporal variability of net primary productivity (NPP) over terrestrial biosphere of India using NOAA-AVHRR based GloPEM model; Indian Soc. Remote Sens. 39(3) 345-353, https://doi.org/10.1007/ s12524-011-0123-1.

Sitch S, Friedlingstein P and Gruber N et al. 2013 Trends and drivers of regional sources and sinks of carbon dioxide over the past two decades; Biogeosci. 11 20113-20177, https:// doi.org/10.5194/bgd-10-20113-2013.

Sitch S et al. 2015 Recent trends and drivers of regional sources and sinks of carbon dioxide; Biogeosciences 12 653-679, https://doi.org/10.5194/bg-12-653-2015.
Sokolov A P et al. 2008 Consequences of considering carbonnitrogen interactions on the feedbacks between climate and the terrestrial carbon cycle; J. Clim. 21 3776-3796, https://doi.org/10.1175/2008JCLI2038.1.

Tang X et al. 2014 How is water-use efficiency of terrestrial ecosystems distributed and changing on earth? Nat. Sci. Rep. 4 7483, https://doi.org/10.1038/srep07483.

Tawde Sayli A and Singh C 2014 Investigation of orographic features influencing spatial distribution of rainfall over the Western Ghats of India using satellite data; Int. J. Climatol. 35(9) 2280-2293, https://doi.org/ $10.1002 /$ joc4146.

Thokchom A and Yadava P S 2016 Carbon dynamics in an Imperata grassland in Northeast India; Trop. Grasslands 4 19-28. https://doi.org/10.17138/TGFT(4)19-28.

Thompson R L and Patra P K et al. 2016 Top-down assessment of the Asian carbon budget since the mid1990s; Nat. Commun. 7 10724, https://doi.org/10.1038/ ncomms10724.

Turner D P and Ritts W D et al. 2006 Evaluation of MODIS NPP and GPP products across multiple biomes; Remote Sens. Environ. 102 282-292.

Wolter K and Timlin M S 1993 Monitoring ENSO in COADS with a seasonally adjusted principal component index; In: Proc. 17th climate diagnostics workshop norman OK NOAA/NMC/CAC NSSL, Oklahoma Clim Survey, CIMMS and the School of Meteorology, University of Oklahoma, pp. 52-57.

Wolter K and Timlin M S 1998 Measuring the strength of ENSO events - How does 1997/98 rank? Weather 53 315324.

Xia L, Wang F, Mu X, Jin K, Sun W, Gao P and Zhao G 2015 Water use efficiency of net primary production in global terrestrial ecosystems; J. Earth Syst. Sci. 124(5) 921-931.

Xiao X, Mellilo J M, Kicklighter D W, McGuire A D, Prinn R G, Wang C, Stone P H and Sokolov A P 1997 Transient climate change and net ecosystem production of the terrestrial biosphere; MIT Joint Program on the Science and Policy of Global Change (No. 2), pp. 1-19.

Zaehle S and Dalmonech D 2011 Carbon-nitrogen interactions on land at global scales: Current understanding in modelling climate biosphere feedbacks; Curr. Opin. Environ. Sustain. 3 311-320, https://doi.org/10.1016/j.cosust. 2011.08.008.

Zhang Z, Xue Y, MacDonald G, Cox P M and Collatz G J 2015 Investigation of North American vegetation variability under recent climate: A study using the SSiB4/TRIFFID biophysical/dynamic vegetation model; J. Geophys. Res. Atmos. 120 1300-1321, https://doi.org/ 10.1002/2014JD021963.

Zhao M S, Heinsch F A, Nemani R R and Running S W 2005 Improvements of the MODIS terrestrial gross and net primary production global data set; Remote Sens, Environ. 95 164-176.

Zhu $\mathrm{H}$ et al. 2016 Evaluation of MODIS gross primary production across multiple biomes in China using eddy covariance flux data; Remote Sens.https://doi.org/10. 3390/rs8050395. 